\title{
Quarantines and Distributive Justice
}

\section{Daniel Markovits}

A dreadful plague in London was,

In the year sixty five,

Which swept an Hundred Thousand Souls

Away, yet I alive!

\section{Daniel Defoe, $A$ Journal of the Plague Year}

$\mathrm{M}$ edical quarantines often threaten the civil rights of the persons whom they confine. This might happen in two ways. First, quarantines might inflict harsh conditions on their occupants; and, second, quarantines might be imposed in an arbitrary or indeed discriminatory manner. These concerns, moreover, are anything but fantastic. Infectious diseases, particularly in epidemic forms, commonly trigger retributive and discriminatory instincts, so that actual quarantines often impose inhumane, stigmatizing, or even penal treatment upon persons who are confined based on caprice or even prejudice. ${ }^{1}$

But quarantines that impose no gratuitous hardships and that are applied pursuant to orderly and non-discriminatory procedures are theoretically possible and also practically available. And such well-run quarantines, especially when they are employed to combat epidemic diseases, cannot plausibly be said to violate the civil rights of the quarantined. Even the staunchest civil libertarian must accept that one person's liberty may be restricted when this is necessary for preventing harm to another. ${ }^{2}$ And well-run quarantines confine only those whose continued integration in the general population has been reasonably adjudged to expose others to infection and, moreover,

Daniel Markovits, J.D., is an associate professor oflawe at Yale Law School. He writes in ethics, political philosophy, and the philosophical foundations of private lawe. impose no burdens beyond those necessary for protecting against this harm. The civil libertarian objection therefore identifies abuses in quarantine administration. It does not apply to quarantines per se.

The appropriate balance between the quarantine power and civil liberties is the subject of a lively ongoing debate, ${ }^{3}$ but libertarian concerns do not exhaust the ethics of quarantines. In particular, quarantines also generate an egalitarian anxiety, which addresses the distribution of the burdens that quarantines impose and worries that this pattern of burden and benefit may be in itself unfair. The egalitarian anxiety, moreover, emphasizes genetic features of quarantines - burdens and benefits associated with the patterns of confinement that quarantines inevitably involve - and so casts a wider net than the more common libertarian objection and, in particular, applies even to wellrun quarantines. This egalitarian concern about quarantines has nevertheless been overlooked in discussions of quarantines, and the ethics of quarantine are in this respect not well understood.

These pages take up the connection between quarantines and distributive justice and elaborate this connection in a way that tends to sow doubt about quarantines. In particular, the argument compares quarantines to vaccinations - an alternative method of combating infectious disease. It suggests that vaccinations, even if they are less efficient than quarantines, are more fair and should perhaps be preferred over quarantines, all-things-considered. Moreover, and more strikingly, the argument asks whether, when vaccinations are available but are not administered, and an outbreak of disease arises, fairness may require allowing the outbreak to spread unchecked rather than employing quarantines to contain it.

I propose, therefore, to open a new thread in the 
ongoing political debate about quarantines - one that proceeds along egalitarian rather than libertarian lines. I do not, however, propose finally to decide the egalitarian argument, certainly not as it applies to particular quarantines in particular cases. Everything in the argument is provisional only - indeed, the argument will raise more questions than it settles. But even provisional conclusions carry weight, and no defense of medical quarantines is complete without answering the distributive challenge posed here.

\section{SECTION I}

\section{Quarantines and Vaccinations}

Quarantines contain infectious diseases by isolating infected and exposed persons from the remainder of the population. ${ }^{4}$ Often this is not the only available means for combating infectious diseases, and quarantines commonly compete with other methods of disease control. In particular, many diseases may be controlled through vaccinations, which allow persons to be exposed to the agents of infection but prevent exposed persons from contracting the diseases. ${ }^{5}$

Both methods of disease control involve costs, of course, including not only the economic costs associated with paying for them but also human and indeed medical costs. Quarantines allow some persons often quite a few persons - to suffer the burdens of contracting the diseases they combat, including persons who become infected within quarantines but would not have been infected in their absence, even if no alternative policy of disease control were adopted in their stead. Moreover, quarantines add to these medical burdens the direct burdens of confinement itself, so that (no matter how intelligently and humanely a quarantine is administered) it is surely worse to live, and indeed to contract an infectious disease, within a quarantine than without it. Vaccinations, for their part, necessarily impose pain and indeed sickness upon persons who are vaccinated, through side effects that range from the prick of the needle, to brief malaise, to serious illness, and even to death.

These costs entail that quarantines compete with vaccinations, in the sense of being substitutes rather than complements for each other, quite possibly in general and certainly on the margin. To see this, one need only to imagine that a case of infectious disease is introduced into a population in which one means of disease control has been adopted and to ask whether the other remains appealing. On the one hand, if all persons have received a perfectly effective vaccine against the disease, then no new infections can occur. Quarantining those persons who have been exposed to the infected person no longer generates any benefits to justify the burdens imposed by the quarantine.
And on the other hand, if all persons who have been exposed to a disease will be perfectly quarantined, so that no new exposures to the disease can occur, then vaccinating those persons who remain unexposed no longer generates any benefits to justify the burdens that the vaccinations involve.

Of course, the choice between these means of combating disease need not always be so stark, and mixed responses to an infection - which combine less general vaccinations with less aggressive quarantines - may perhaps sensibly be employed. ${ }^{6}$ Nevertheless, the two strategies compete even within these mixed responses. Quarantines are not needed to protect persons who are vaccinated and vaccinations are not needed to protect against the quarantined, so that an increase in either prong of a mixed response diminishes the demand for the other. And once again, because both quarantines and vaccinations are burdensome, incremental successes of one method of controlling an infection once again undermine the justification for incremental increases in the other.

This makes it natural to ask which means of controlling infectious diseases policy-makers should, allthings-considered, prefer.

\section{SECTION II}

\section{Aggregate and Individual Burdens}

Quarantines will often control disease more efficiently than vaccinations. That is, quarantines will often involve a smaller sum of costs of disease and costs of prevention. In particular, quarantines enjoy two structural advantages over vaccinations with respect to their efficiency at controlling disease. Both advantages are connected to the fact that vaccinations must typically be administered prior to exposure in order to be effective, either because this is medically necessary to confer immunity or because epidemiological patterns develop too rapidly and unpredictably to allow for practical and reliable post-exposure vaccination regimes. ${ }^{7}$ This reduces the efficiency of vaccinations in two ways. First, it means that vaccinations must typically be administered in advance of an outbreak of infection, ${ }^{8}$ so that the costs of vaccination, including the medical costs, must be borne even when no outbreak actually occurs. ${ }^{9}$ And second, it means that vaccinations must be administered widely, and perhaps even to an entire population, so that the costs of vaccination must be borne by persons who would not be exposed even to such outbreaks as did occur. ${ }^{10}$ Quarantines are in both these ways much more narrowly targeted than vaccinations. They are applied only after the beginning of an outbreak and therefore impose no costs in case no outbreak ever occurs. And they are applied only to persons who might be infect- 
ed and therefore impose no costs upon persons known to be unexposed. Each of these differences implicates vaccinations in forms of waste that quarantines avoid and therefore tends to tip the balance of aggregate burdens in quarantines' favor. ${ }^{11}$

A simple stylized example illustrates both points and serves to fix ideas for purposes of the argument to come. Imagine that a population of ten million persons faces a one in five chance of an epidemic outbreak of an infectious disease. If an epidemic occurs and nothing is done to combat the disease, two-anda-half million persons will eventually become infected. Suppose further that the disease may be contained in two ways. First, quarantining the first one million persons who are exposed will protect the remaining nine million from exposure, although at a cost: 650 thousand of the quarantined persons will contract the disease; ${ }^{12}$ and all one million will bear the burdens of confinement, which are $1 / 10$ the burden of suffering the disease. Second, vaccinating the entire population in advance of any outbreak can prevent infections entirely, although the vaccinations are themselves burdensome. They are expensive and painful and, more importantly, involve significant medical side effects. The per-person burden of vaccination is $1 / 40$ as bad as suffering the actual disease.

On these facts, the expected aggregate burden associated with the disease if nothing is done to control it - namely 500,000 infections ${ }^{13}$ - is greater than the expected aggregate burden of combating the disease through vaccinations - the equivalent of 250,000 infections ${ }^{14}$ - which is greater than the expected aggregate burden of employing a quarantine to combat the disease - the equivalent of 150,000 infections. ${ }^{15}$ These numbers are set out in Table One.

The precise magnitudes of these aggregate costs of course reflect the assumptions of the particular example from which they are drawn. ${ }^{16}$ Nevertheless, the example vividly illustrates a broader, structural point: insofar as outbreaks of disease are unlikely, and quarantines may be targeted narrowly, quarantines will tend to minimize the aggregate costs associated with infectious disease.

Table One

Aggregate Costs of Disease Plus Disease Control

$\begin{array}{llll}\text { Policy } & \text { No Response } & \text { Vaccination } & \text { Quarantine } \\ \text { Costs of Disease } & 2.5 \mathrm{M} \text { cases } & 0 \text { cases } & 650,000 \text { cases } \\ \text { Costs of Disease Control } & 0 & 10 \mathrm{M} \text { vaccines } \approx & 1 \text { M confined } \approx \\ & & 250,000 \text { cases } & 100,000 \text { cases } \\ \text { Chance of Bearing Costs } & 1 / 5 & 1 & 1 / 5 \\ \text { Expected Aggregate Costs } & 500,000 \text { cases } & \approx 250,000 \text { cases } \approx 150,000 \text { cases }\end{array}$

But even as they minimize the aggregate costs associated with infectious disease, quarantines spread these costs less evenly than vaccinations. In particular, the greatest individual burdens to which persons are exposed will be greater under a quarantine regime than under a regime of vaccinations. ${ }^{17}$ This is the mirror image of quarantines' efficiency, the drawback of allowing a disease to strike and seeking only to prevent its spread.

Unlike vaccinations, quarantines countenance that some persons might become infected by the diseases that they combat. Indeed, quarantines actually increase the greatest individual burdens associated with disease in two ways. First, practicable quarantines, especially in connection with large-scale outbreaks of disease, will tend to confine persons who have merely been exposed (but not infected) together with persons who do carry a disease and threaten to pass it on. And this practical need to confine the sound with the sick ${ }^{18}$ will tend to cause the proportion of persons who become infected within quarantines to exceed the proportion of persons who would be infected in the general population in the absence of the quarantines, so that as yet uninfected persons who are confined will face a greater risk of infection than they (or indeed anyone) would face under a vaccination regime or indeed if nothing were done to combat a disease. ${ }^{19}$

Moreover, although the proportion of persons who become infected within quarantines may in principle be reduced by good quarantine management - and modern quarantine doctrine expressly calls for isolating persons who become sick within quarantines and providing them with all available medical treatments $^{20}$ - this aspiration does not offer general, practical relief from the burdens of quarantines. Noncompliance with voluntary quarantines will often render enforcement necessary, and only group quarantines can effectively be enforced. ${ }^{21}$ Furthermore, as the number of exposed persons grows, the venues capable of hosting quarantines will tend to fill up, impressing the quarantined into increasingly close quarters (and perhaps even forcing contacts between merely exposed persons and those who are already symptomatic), so that the within-quarantine rate of infection will become increasingly difficult to control. ${ }^{22}$

Accordingly, even as quarantines reduce the total cases of the diseases they contain, and so also the average risk of infection, measured across the entire population, they increase the greatest risk of infection that any person faces. ${ }^{23}$ The stylized example reflects this - it assumes that 65 percent of 
persons within the quarantine will become infected and 25 percent of persons will become infected in an unvaccinated population in the absence of a quarantine.

And second, quarantines add the burdens of confinement itself to the risks of becoming infected. These direct costs of confinement to quarantines generally will be significant. The loss of liberty and the economic costs (for example, of lost wages) that all quarantines necessarily impose are only the most obvious burdens that follow immediately from confinement and cannot be undone by benevolent administration. Another direct cost of confinement is the separation, and indeed exile, from the broader world and its interests and projects that so afflicted the quarantined citizens in the Oran of The Plague. When infectious diseases are less medically severe, the burden of lost liberty will be substantial compared to the costs of infection (indeed, it will likely be relatively more burdensome than the example credits). And as infectious diseases become more serious, isolation will become relatively more burdensome and will come to include not just detachment from social life but also the desperate, existential loneliness associated with suffering or dying apart from the people one loves that so interested Camus.

Finally, these two burdens - the increased within-quarantine risks of infection and the direct costs of confinement - are related in a way that frustrates efforts to eliminate both at once. ${ }^{24}$ Measures to control infection within quarantines will themselves increase both elements of the burdens of confinement. These measures will necessarily increase the extent to which quarantined persons are separated from each other, and (even if they are intelligently and humanely administered) they will therefore also substantially increase both the loss of liberty and the isolation that quarantines impose upon their inmates. This is most vividly true of efforts to eliminate within-quarantine transmissions of disease by holding all quarantined persons in solitary confinement, but efforts to achieve more moderate reductions in within-quarantine infection rates through less dramatic forms of withinquarantine isolation and control will have similar effects. These are of course generic speculations only, and they cannot possibly serve to assess either element of the actual costs imposed by any specific quarantine. But they are sufficient to show that the various burdens associated with quarantines - the direct costs of confinement and the additional costs associated with increased within-quarantine rates of infection are intertwined in such a way that reducing one increases other, so that the burdens of being quaran- tined cannot all be eliminated, or even made small, at once.

Accordingly, even when quarantines are more efficient than vaccinations, the greatest individual burdens that they involve exceed the greatest individual burdens associated with vaccinations, or indeed with doing nothing to combat a disease. This is once again reflected in the stylized example, in which the greatest individual burdens imposed by a quarantine - the costs of confinement plus a $65 \%$ chance of infection exceed the greatest individual burdens associated with doing nothing to combat disease - a $25 \%$ chance of infection - which exceed the greatest individual burdens associated with vaccinations - the equivalent of $1 / 40$ of the burden of infection. These numbers are set out in Table Two. ${ }^{25}$
Table Two

\begin{tabular}{|c|c|c|c|}
\hline \multicolumn{4}{|c|}{ Greatest Individual Burdens at Time of Quarantine } \\
\hline Policy & Vaccination & None & Quarantine \\
\hline $\begin{array}{l}\text { ndividual Burdens } \\
\text { f Disease }\end{array}$ & none & $\begin{array}{l}25 \% \text { chance } \\
\text { of infection }\end{array}$ & $\begin{array}{l}65 \% \text { chance } \\
\text { of infection }\end{array}$ \\
\hline $\begin{array}{l}\text { ndividual Burdens } \\
\text { of Disease Control }\end{array}$ & $\approx .025$ infection & none & $\approx 0.10$ infection \\
\hline ndividual Total & $\approx 0.025$ (infection) & 0.25 (infection) & $\approx 0.75$ (infection) \\
\hline
\end{tabular}

These differences will seem most practically urgent when the costs of confinement are large relative to costs of infection and when quarantines involve relatively large increases in the risks of infection faced by the persons whom they confine. Once again, the precise magnitudes in the table depend on the assumptions of the particular example from which they are drawn. However, the pattern that the table reports is unlikely to be merely an artefact of the peculiar assumptions of the stylized example. Quarantines generally will increase the greatest individual burdens associated with outbreaks of infectious disease. ${ }^{26}$

Taken together these speculations emphasize a basic feature of quarantines that may now be simply stated. Even quarantines that minimize the aggregate burdens of infectious disease also concentrate these burdens upon a few persons, who bear greater individual burdens than anyone would do under alternative policies. No person is as badly off, under a vaccination regime or indeed under a regime that allows an infectious disease to spread unchecked, as a person who is confined to a quarantine.

\section{SECTION III}

\section{Distributive Intuitions}

The control of infectious diseases (at least for the 
cases whose epidemiology displays the patterns that I have described and that are reflected in the stylized example) therefore involves a familiar choice between efficiency and distribution. This choice arises in many other circumstances as well, and other prominent practices that generate analogous choices between efficiency and distribution should give pause to quarantine enthusiasts. In these cases, analogous efforts to reduce the total size of a burden by concentrating it upon a few unfortunate persons appear, intuitively, to be unacceptably unfair. Indeed, the examples suggest that fairness requires precisely the opposed response, namely that harms be spread to reduce the greatest burden any individual person must suffer, even at the cost of increasing the aggregate burden borne overall. ${ }^{27}$

Certain religious practices, which employ ritual sacrifice in order to save some collective enterprise from failure, present perhaps the starkest case of this damning analogy. A familiar example is Agamemnon's plan to sacrifice Iphigenia in the service of the Trojan War. ${ }^{28}$ We no doubt disapprove of such practices in part because we reject the religious ideas in whose service they arise and therefore deny that the sacrifices they contemplate will be effective and perhaps even that the ends these sacrifices serve are desirable. But we also object to the practices for another reason, namely that we regard the distribution of burdens that these practices produce - in which one person suffers an acute burden in order to protect many others from an overall greater but more diffusely distributed harm - as deeply, and offensively, unfair to the sacrificial victim (even if the victim is chosen at random). Indeed, this sense of unfairness is reflected in the language we apply to such cases: the word "scapegoat" and its cognates convey the injustice and degradation that they involve. ${ }^{29}$ Medical quarantines reprise the distributive pattern associated with sacrifice, but without cover of religious ideas. ${ }^{30}$ And while the substitution might render the claims of medical quarantines more credible, and the interests quarantines serve more appealing, they cannot make the sacrifices quarantines impose fair.

Moreover, a second analogy solidifies this intuitive doubt about the fairness of quarantines and connects the intuition to more theoretically articulate ideas about fair distribution. Every society includes some persons who are, through no fault of their own, ${ }^{31}$ unable to create goods or perform services that others value. These persons lack the mental or physical talents, or the educational opportunities, needed to become economically productive - they bear an economic disability whose costs are measured in terms of the gap between their productivity and the productivity of an average person. These costs need not, of course, be borne exclusively by those who are themselves unproductive. Instead, social welfare programs, funded by progressive taxes, may relieve unproductive persons of a part of the burden of their own economic disability. But even as they spread the burdens of economic disability more evenly, such redistributive policies create familiar distortions in the economies of societies that adopt them, and these distortions reduce the productivity even of more productive persons. Moreover, the economic distortions that accompany redistribution depress the output of the productive by more than the redistribution improves the condition of the unproductive, so that redistribution causes the productivity of the economy as a whole to decline. $^{32}$ Markets that are free of redistributive interventions, by contrast, maximize the economy's aggregate output, ${ }^{33}$ but only - because they set all persons' wages at their marginal products - at the cost of concentrating the burdens of economic disabilities directly on the persons who display them.

This case casts further doubt on the fairness of the distributive patterns associated with quarantines. Very few people think it fair to abandon redistribution in the single-minded pursuit of economic efficiency, leaving the burdens of economic disabilities concentrated entirely upon those who exhibit them. Indeed, the most prominent contemporary theory of economic justice - the theory that culminates in John Rawls's difference principle - adopts the conceptual opposite of the singleminded pursuit of efficiency. ${ }^{34}$ Whereas perfectly efficient markets accept any concentration of the burdens of economic disability in the service of the single-minded pursuit of minimizing the total burdens that the disabilities cause, the difference principle insists that fairness requires accepting any increase in this total burden in the service of minimizing the most concentrated, greatest burden that any individual person must bear. ${ }^{35}$

Indeed, the analogy to quarantines may be emphasized by recasting the economic case through a medical metaphor. One might say, applying medical language figuratively to the economic arena, that the inability to be economically productive constitutes a kind of economic disease and that redistributive policies, even as they improve the lot of those who suffer the disease, increase the total cost of economic disabilities by causing them to infect otherwise productive persons, who become themselves less productive in the face of the distortions that redistribution necessarily involves. The only way to prevent such infection and the associated further decline in overall productivity is to reject redistributive policies in favor of the economic equivalent of a quarantine: an undistorted market that isolates the economically unproductive 
and, by paying all persons their marginal products, leaves them to bear the entire costs of their economic disease. The analogy to the medical case is therefore complete: like medical quarantines, perfectly efficient markets minimize the total harms caused by economic disability; but also like medical quarantines, they secure this result by concentrating these harms upon the persons of an unfortunate few, who are each burdened more heavily than anyone would be under more redistributive policies, notwithstanding the fact that the total burdens associated with such policies would be greater.

These two analogies cast doubt upon medical quarantines. The first, religious analogy emphasizes the self-indulgent aspect of quarantines - the fact that the unexposed subject the exposed to a worse fate than that from which they protect themselves. And the second, economic analogy entrenches and elaborates upon the skeptical intuitions generated by the first, by embedding these intuitions within a familiar and dens, they make no suggestion that those who are preferred are more valuable, $\ddot{u} b e r h a u p t,{ }^{36}$ than those who are disfavored. Quite to the contrary, when quarantines seek to minimize aggregate harm, they count equal contributions to this aggregate equally, regardless of the identities of the persons through whom the contributions arise. Quarantines therefore accept equality in the sense captured by Bentham's famous dictum "everybody to count for one, nobody for more than one." 37 Quarantines, at least when they are non-discriminatory, oppose ideologies of tribe, caste, and class.

But even though quarantines allow that each person's life is as important as every other's in one way, the conception of equality that they reflect remains inadequate to the problem of distributive fairness that quarantines raise. This marginalist conception of equality treats persons equally as contributors, on the margin, to an aggregate benefit or burden - in the case of medical quarantines, to the total burden of disease. But the aggregate, and not the individual con-

\section{Our more general intuitions reject policies and practices, such as quarantines, that reduce an aggregate burden by concentrating harms upon the worst-off and indeed support policies, like vaccinations, that spread a burden to reduce the greatest individual harms, even at the cost of increasing aggregate harm.}

much-discussed context, in which the distributive patterns associated with quarantines are once again thought unfair. Although medical quarantines themselves may seem intuitively appealing, the broader approach to aggregation and distribution that quarantines embody fares less well, and indeed is emphatically rejected, in other, structurally analogous circumstances. Our more general intuitions reject policies and practices, such as quarantines, that reduce an aggregate burden by concentrating harms upon the worstoff and indeed support policies, like vaccinations, that spread a burden to reduce the greatest individual harms, even at the cost of increasing aggregate harm.

\section{SECTION IV}

\section{Distributive Theory}

Moreover, these general intuitions may be given a powerful theoretical development, which further isolates and undermines the intuitive case for medical quarantines. Quarantines, in all these cases, violate a basic egalitarian principle of distributive fairness.

The varieties of quarantine involved in the economic, religious, and medical cases that I have imagined do not, to be sure, reject equality entirely. Although quarantines countenance uneven (and indeed sometimes extremely uneven) allocations of benefits or bur- tributors, remains the marginalist view's ultimate concern throughout, so that the marginalist view approaches each person merely as a contributor to this total and does not accord any personal benefit or burden independent concern. And the marginalist conception of equality therefore fails, as John Rawls famously observed, "to take seriously the separateness of persons," ${ }^{38}$ namely that persons are not merely conduits into an aggregate of benefit or burden that dominates moral concern but are instead individuals, each of whose lives has distinct and free-standing moral value and commands separate moral attention.

When the marginalist conception of equality ignores the separateness of persons in this way, it ignores the feature of moral life out of which the problem of fair distribution arises in the first place and which belongs among the basic data to which a conception of distributive fairness must apply, and the marginalist conception is therefore quite literally incapable of taking a distributive view. ${ }^{39}$ This failure, moreover, receives direct expression in the marginalist conceptions's enthusiasm for quarantines: the marginalist conception of equality readily approves even of quarantines that impose enormous burdens on a few persons in order to sustain tiny, but aggregatively greater, benefits to many others precisely 
because it is structurally incapable of taking notice of the free-standing moral claims of the persons who must bear the burdens.

The marginalist failure to consider distributions including, once again, in the case for medical quarantines - appears, by the light of the separateness of persons, as unacceptable twice over. To begin with, one consequence of the separateness of persons is that moral justifications must address themselves to the several persons who are affected by the policies that they justify, taken one at a time. But marginalist moral argument with its exclusive emphasis on aggregates ignores these individual demands for justification imposed by the separate persons whom a policy effects, including by those upon whom the policy concentrates burdens. Moreover, the aggregates that marginalist arguments do emphasize - including the aggregates of health and disease to which the case for medical quarantines refers - appear, by the light of the separateness of persons, as highly dubious objects for moral concern. The total benefits and total harms that these aggregates calculate are not actually good or bad for anyone because they are, quite literally, not experienced by anyone. ${ }^{40}$ And it is hard to see how justifications - including of medical quarantines - that must be addressed to individual, separate persons can possibly succeed if they proceed in terms that do not matter to any of the persons whom they must address. The marginalist case for medical quarantines therefore precisely reverses the pattern of attention that moral justification, and in particular distributive fairness, requires: it ignores what is essential to fairness the individual burdens that quarantines impose and the individual claims to justification that these burdens underwrite; and it emphasizes what is incidental to fairness - the aggregate burden of disease.

The separateness of persons not only undermines the marginalist case for medical quarantines but also suggests a contrary approach. This approach generalizes upon the earlier examples in which I proposed that quarantine-like policies are rejected in favor of policies that spread rather than concentrate harms and renders the intuitions that these examples involve theoretically articulate. If policies must be justified to the persons whom they affect, from each of these persons' individual points of view, then the more challenging of these demands for individual justification will naturally be those issued by persons whom the policies in question would render worse off, since these are the persons from whose points of view the policies will naturally seem less acceptable. This thought underwrites a prioritarian conception of dis- tributive fairness - so called because its recognition that distributive arrangements must be especially solicitous of the persons to whom they are least congenial in effect grants priority to the worse-off. The prioritarian account therefore endorses spreading rather than concentrating burdens, even when the spreading is accompanied by some greater aggregate of harm, insofar as such spreading reduces the harms borne by the worse-off.
The prioritarian case against quarantines is strongest when distributive principles are applied, as I have applied them, at the moment of the quarantine decision rather than either earlier or later.

The distributive objection to medical quarantines that I have been developing is now in place. Even when quarantines minimize the total burden of an infectious disease, they achieve this by concentrating the infection in a class of persons who must bear greater individual burdens than any persons would bear under a regime of vaccination or indeed even if nothing were done to combat the infection. Structurally analogous efforts to reduce the total size of other burdens by concentrating them upon a few persons appear unfair, however, and fairness seems, intuitively, to require spreading rather than concentrating burdens. Moreover, these thoughts reflect more than just intuitive or analogic reasoning, but instead invoke a substantial theoretical argument concerning prioritarian distributive fairness: they take note of, and give concrete expression to, a fundamental feature of the moral life of persons that the traditional case for quarantines neglects. The intuitive appeal of quarantines therefore conflicts both with neighboring intuitions and with more theoretically articulate and compelling ideas about fairness.

\section{SECTION V}

\section{Framing Distributive Judgements}

Quarantines offend both intuitive and more reflective ideas about distributive justice. But the argument up to this point rests upon a hidden assumption, and it is time to bring that assumption out into the open and subject it to scrutiny. ${ }^{41}$ The argument that I have developed assesses the distributive fairness of quarantines, and measures the individual benefits and burdens that they involve, at the moment of the quarantine decision rather than earlier - when the risk that an infection may be introduced into a population becomes known but before the infection actually 
appears - or later - when all risks associated with a disease have resolved themselves and persons are, finally, either infected or not. And it may seem strange, or at least unmotivated, for the argument to frame the question of distributive fairness in medias res, as it were, rather than ex ante or ex post.

Moreover, the prioritarian case against quarantines is strongest when distributive principles are applied, as I have applied them, at the moment of the quarantine decision rather than either earlier or later. Indeed, the prioritarian case against quarantines substantially depends upon taking this intermediate point of view, so that the previously unargued assumption that distributive principles should be applied in medias res stands in need of a defense. Certainly it is insufficient to observe simply that the measures of individual burden that I have employed are the measures that apply at the moment at which quarantines might actually be imposed: it is after all possible, even at that moment, to look backwards or forwards and view a quarantine in the context of the overall sequence of events to which it belongs. Instead, the distributive objections to quarantines that I have developed depend upon showing that the intermediate point of view from which my argument assesses the individual burdens of the several approaches to infectious disease may be defended by reference to prioritarian principles of distributive fairness, including most importantly by reference to the prioritarian idea of the separateness of persons.

The two components of this supplemental argument are not equally important to the criticism of quarantines, however, because the suggestions that prioritarian principles be applied ex ante and ex post are not equally threatening. The greater threat to the distributive argument against quarantines comes from the suggestion that prioritarian distributive principles should measure the individual burdens of disease $e x$ ante, before any outbreak of infectious disease has yet occurred. When individual burdens are assessed $e x$ ante, then the distributive objection to quarantines, including even the distributive preference for vaccinations over quarantines, falls apart altogether, and efficient quarantines necessarily also appear fair. The lesser threat comes from the suggestion that priortarian principles should measure the individual burdens of disease ex post, when all risks have resolved themselves and persons are finally infected or not. When individual burdens are assessed ex post, the distributive objection to quarantines is merely weakened: even though vaccinations continue to appear fairer than quarantines, fairness seems no longer to condemn resorting to quarantines as a secondbest alternative in case a disease strikes a population in which vaccinations have, unfairly, been foregone.

As it happens, the answers that the prioritarian can give to proposed departures from measuring individual burdens in medias res are powerful in proportion to the threats that these departures pose: the ex ante point of view may be firmly rejected, whereas the arguments against the ex post point of view remain more speculative. The criticism of quarantines that I have developed therefore remains robust at its core, even if it becomes a little uncertain at the edges. In particular, the distributive case for preferring vaccinations even over more efficient quarantines remains strong, whereas the case against adopting quarantines as a second-best measure, when an infection strikes an unvaccinated population, is a little weaker.

\section{SECTION VI \\ Unrestrained Aggregation and the Ex Ante Point of View}

First, if individual burdens are assessed ex ante when the possibility of an outbreak of infection becomes known but before any outbreak actually occurs - then the prioritarian objection to quarantines falls apart entirely. When individual burdens are assessed ex ante, efficient quarantines, which minimize aggregate burdens, also necessarily minimize individual burdens and therefore also necessarily appear most fair under prioritarian principles.

In this case, the burdens that each person faces under a quarantine policy must be discounted by the possibilities that no outbreak will ever occur and, if an outbreak does occur, that only other people will be burdened by it. In the example, the greatest individual burden to arise under a quarantine regime is the burden of becoming infected within the quarantine, discounted by the one in five chance of an outbreak, compounded by the one in ten chance of being quarantined in case an outbreak occurs, compounded by the 65 percent chance of becoming infected if quarantined. Analogously, the greatest individual burden to arise if nothing will be done to combat an outbreak, assessed from the ex ante point of view, is the burden of becoming infected, discounted by the one in five chance of an outbreak, compounded by the 25 percent chance of becoming infected in case of an outbreak. Finally, because vaccinations must be administered in advance of an outbreak their burdens are not discounted at all, so that the greatest individual burden associated with a vaccination regime remains equivalent to $1 / 40$ of the burden of infection. These numbers appear in Table Three.

As the table indicates, when individual burdens are measured from the $e x$ ante point of view, the greatest individual burden associated with a quarantine 
Table Three

Greatest Individual Burdens Assessed Before Any Outbreak (Ex Ante)

$\begin{array}{llll}\text { Policy } & \text { None } & \text { Vaccination } & \text { Quarantine } \\ \begin{array}{l}\text { Individual Burdens } \\ \text { of Disease }\end{array} & 0.05 \text { (infection) } & \text { none } & 0.013 \text { (infection) } \\ \begin{array}{l}\text { Individual Burdens } \\ \text { of Disease Control }\end{array} & \text { none } & \approx 0.025 \text { (infection) } & \approx 0.0013 \text { (infection) } \\ \begin{array}{l}\text { Individual Total } \\ \text { non (infection) }\end{array} & \approx 0.025 \text { (infection) } & \approx 0.0143 \text { (infection) }\end{array}$

individual burden is simply an equal share of the aggregate burden. This even spreading is necessary to ensure that the most efficient response to disease - the response with the smallest aggregate burden - also involves the smallest individual burdens and therefore best satisfies prioritarian principles. If, instead, certain persons are more likely than others to be exposed to outbreaks of disease and therefore also more likely to be quarantined and to become infected, then the greatest ex ante individual burdens associated with more efficient quarantines will no longer necessarily be smaller than the greatest $e x$ ante individual burdens of less efficient vaccinations, since the latter, even if larger on average, ${ }^{43}$ are more evenly distributed. ${ }^{44}$

And in every actual society, and at every actual time before an infectious disease is introduced, the risks associated with possible outbreaks of infectious disease and the risks of being confined by a quarantine policy following such outbreaks are not in fact spread evenly across all persons. These risks instead track any number of familiar demographic traits - urban residence, poverty, immigrant status, and so on. And insofar as these risks are uneven, the greatest $e x$ ante individual burdens associated with quarantines - the risks faced by city dwellers, the poor, or newcomers may indeed exceed the greatest of the more evenly distributed individual burdens associated with less efficient vaccinations. Quarantines entrench existing inequalities in the individual burdens associated with infectious disease whereas vaccinations do not, and insofar as these existing inequalities are substantial, quarantines appear less fair than vaccinations even when individual burdens are assessed prior to any actual outbreak of infection, even, that is, from the $e x$ ante point of view.

Of course, it is always possible to assess individual burdens from an earlier and earlier perspective. And eventually this perspective will come to obscure not only narrow facts about a particular outbreak of disease and whom it exposes but also the differentiating factors that affect individual chances of falling within the orbit of potential outbreaks (and in whose shadow the uneven distribution of the burdens associated with quarantine policies arises). Certainly there will come a point at which all such facts are obscured, and at which it becomes impossible to know where diseases are most likely to be introduced and who is most likely to be quarantined. From sufficiently far ex ante, therefore, prospective burdens do indeed appear to spread evenly across persons.

But even as this extreme ex ante point of view produces a measure of individual burdens according to 
which quarantines conform to prioritarian distributive patterns, it quite literally abandons the basic ideal (involving the separateness of persons) that underwrites the prioritarian account of just distribution. Distributive justice insists on assessing fairness in terms of differences in the burdens borne by individual and distinct persons. But as burdens are measured from an increasingly early point of view, the bearers of these burdens become increasingly less distinctively individual persons, because they lose all the attributes that individuate them, and they appear, instead, as undifferentiated shareholders in a common burden. And accordingly, as the ex ante assessment of individual burdens moves earlier and earlier, it will seem less and less relevant to prioritarian distributive justice. Indeed, when individual burdens are assessed from the extreme ex ante point of view (the point of view from which efficient policies necessarily minimize individual burdens), the prioritarian outlook ceases to present a real contrast to the marginalist approach at all. The equivalence between prioritarian principles applied ex ante and marginalist principles is not limited to the conclusions that they generate but also encompasses the form of argument by which these conclusions are reached - in each case, there is a denial of the separateness of persons. The suggestion that individual burdens should be measured $e x$ ante therefore does not satisfy so much as pre-empt prioritarian principles, and it cannot answer the distributive argument favoring vaccinations over quarantines. ${ }^{45}$

Moreover, the prioritarian argument against assessing individual burdens from the ex ante point of view may be given a second, more concrete development also. The proposal that individual burdens be assessed $e x$ ante treats unresolved risks - that an outbreak of infectious disease will occur, that a person will be exposed to the infection, that an exposed person will become infected - as in themselves salient for purposes of distributive justice, and indeed as forestalling any distributive concern with the risks' eventual resolutions. But the prioritarian ideal suggests, instead, that distributive principles should ordinarily look through risks to the outcomes that arise when the risks do or do not eventuate. Facing a risk of being harmed does not in itself make a person worse off in a way that triggers distributive concern: as T.M. Scanlon has proposed, the "ultimate stakes," from the point of view of distributive justice, are not who bears risks but rather who is harmed. ${ }^{46}$

Although exposure to a risk of harm may, to be sure, be treated as a piece of bad or good fortune for the persons who bear the risk, all such risks and chances will eventually resolve themselves into certainties, in which harms are suffered or not. This resolution is itself a second piece of bad or good fortune that follows the initial fortune of bearing the risk. And this second piece of fortune (how the risk is resolved) will naturally seem to swallow up the first (the imposition of the unresolved risk), so that once a risk has been resolved into one outcome or the other, a person who faced the risk and its resolution has been treated no differently by fate, in toto, from a person who faced this eventual outcome as a certainty from the get-go. Thus persons who faced equivalent risks but enjoy different outcomes bear different fortunes overall and persons who faced different risks but enjoy equivalent outcomes bear the same fortunes. According to this approach, someone who faces a risk of harm is not properly described, from the perspective of distributive justice, as being worse off than someone who faces no risk or better off than someone who faces certain harm. Instead of falling between these two certain outcomes, the risky case is assimilated, for purposes of distributive fairness, to one certain outcome or the other, although which is not known until the risk resolves itself. 47

Finally, this emphasis on ultimate outcomes may be naturally connected to the intuitive foundations of prioritarian distributive justice, and especially to prioritarianism's emphasis on the separateness of persons and its characteristic special sympathy for the less fortunate. The ex ante point of view ignores that persons may yet be separated by good or bad fortune after it has turned its attention away, even as this later fortune may swallow up the earlier fortune on which $e x$ ante judgments of distributive priority are based. Measures of individual burdens that proceed from the $e x$ ante point of view therefore stop attending to persons' individual positions before fortune has finished separating them and run its full course, and indeed before fortune's most crucial interventions. But the prioritarian concern for the less fortunate attaches not to synchronic snapshots of persons' distinct fortunes as they stand at a particular moment in time but rather to diachronic accounts of persons' fortunes overall. Prioritarian principles insist, after all, on respecting the separateness of persons and not of experiences. ${ }^{48}$ And from this diachronic point of view, risks will always be resolved into certain outcomes, which therefore alone matter to distributive fairness. Once again, the suggestion that individual burdens should be measured ex ante does not satisfy prioritarian distributive principles and cannot answer the distributive argument favoring vaccinations over quarantines.

These considerations secure the distributive preference for vaccinations over quarantines: they explain 
why the distributive fairness of quarantines cannot be rehabilitated by measuring individual burdens from the $e x$ ante point of view. ${ }^{49}$

\section{SECTION VII \\ The Limits of Fairness and the Ex Post Point of View}

In addition to proposing that vaccinations are fairer than quarantines, my initial argument suggested that if an infectious disease strikes an unvaccinated population, then quarantines might be less fair even than doing nothing to prevent the spread of the disease. And the two arguments just rehearsed may seem less friendly to this second conclusion than to the first. Both arguments push distributive fairness steadily towards measuring individual burdens later and later. Indeed, it may seem that they push right past the in medias res assessments of individual burdens on which my initial treatment of quarantines depends and all the way to the ex post point of view. And if distributive justice should indeed measure individual burdens ex post then quarantines might yet be second-best responses to infectious disease in cases in which vaccinations have (unfairly) been foregone.

To see this, return again to the stylized example and consider the individual ex post burdens that the example involves. When individual burdens are measured from the ex post point of view, the smallest individual burden (by far) continues to arise under a vaccination regime - these are the burdens of being vaccinated, namely $1 / 40$ of the burden of infection - so that vaccinations appear once again to be the fairest response to the infectious disease. Moreover, the individual burden associated with doing nothing to combat the disease - namely, the burden of infection standing alone - continues to be smaller than the individual burden associated with quarantines - namely the burden of infection plus the direct cost of confinement (equivalent, in the example, to a further $1 / 10$ of the burden of infection). But the difference between the individual burdens that arise in these two cases appears much smaller from the ex post point of view than it did when viewed in medias res. In particular, the increased within-quarantine risk of infection falls away, so that only the direct costs of confinement continue to make quarantines more individually burdensome than doing nothing to combat a disease. And accordingly, although quarantines continue to appear less fair than vaccinations when individual burdens are measured from an ex post point of view, the unfairness seems much less pressing. These burdens are recorded in Table Four.
Even prioritarian principles of distributive fairness do not rule out every reference to numbers. In particular, it is open to a prioritarian to think that a person faced with a determinate choice between relieving a larger and a smaller group of persons of equivalent individual burdens should save the larger group, and indeed on the ground that the larger group contains more persons. ${ }^{50}$ The prioritarian may reach this conclusion without making any reference to the ideas of aggregate burden whose moral significance she denies, simply by matching the claims to aid of the individual persons in the two groups until the smaller group is exhausted and the larger group's members continue to present unopposed claims for aid. ${ }^{11}$ Rather than counting each claim to be saved proportionally toward some aggregate claim (as on the marginalist view), this approach to numbers insists that each person's individual, independent claim to be saved be separately considered and rejected only on the balance of another person's individual, independent claim that is incompatible and at least as pressing. The larger number should be saved, for the prioritarian, not because their claims added to a greater aggregate but for the very different reason that when this person-by-person balancing procedure is applied, some claims to save the larger group survive even after all the claims to save the smaller group have been counterbalanced, or used up, as it were. ${ }^{52}$ If the ex post burdens of disease under quarantines are indeed equivalent to the burdens that arise when the disease is allowed to spread unchecked, then the choice between imposing a quarantine and doing nothing to combat a disease presents just such a choice between subjecting a smaller and a larger group of persons to equivalent harms. ${ }^{53}$ Prioritarian person-by-person balancing approves of confining the harms to the smaller group, as quarantines do.

If individual burdens are assessed ex post, the distributive argument against adopting quarantines even as a second-best policy depends, therefore upon the additional direct costs of confinement that quarantines impose upon those who become infected within them. And especially in connection with serious dis-
Table Four

\begin{tabular}{|c|c|c|c|}
\hline \multicolumn{4}{|c|}{ Greatest Individual Burdens Ultimately Borne (Ex Post) } \\
\hline Policy & Vaccination & None & Quarantine \\
\hline $\begin{array}{l}\text { Individual Burdens } \\
\text { of Disease }\end{array}$ & none & infection & infection \\
\hline $\begin{array}{l}\text { Individual Burdens } \\
\text { of Disease Control }\end{array}$ & $\approx .0025$ infection & none & $\approx 0.1$ infection \\
\hline Individual Total & $\approx 0.025$ (infection) & infection & $\approx 1.1$ (infection) \\
\hline
\end{tabular}


eases, it may be thought artificial, or at least unsatisfying, to hang the unfairness of quarantines on this relatively slim difference between the burdens of suffering infection within and without a quarantine. Even though becoming infected within a quarantine remains, strictly speaking, worse than simply becoming infected, the two may be thought equivalent for purposes of distributive fairness, which may be thought to group burdens into equivalence classes trivial, small, moderate, large, severe - in a way that places these two burdens into the same class. And in this case, prioritarianism may approve of quarantines under the person-by-person balancing approach just described, as a method of saving the greater number from equivalent individual harms when a disease strikes an unvaccinated population.

These thoughts cannot of course reinstate any general enthusiasm for quarantines, nor can they sustain the sense that quarantines are straightforwardly justified that characterizes the marginalist view. They represent at most a partial distributive vindication of quarantines, and they rest on a view of the direct costs of confinement that might, in light of earlier structural arguments, be thought conservative. But when individual burdens are assessed ex post, quarantines may plausibly be said, contrary to the earlier argument, to satisfy prioritarian principles of fairness, although only as second-best alternatives after vaccinations have been unfairly foregone. At the very least, the most extreme distrbutive objection to quarantines seems to lose its practical urgency.

The same considerations that explain why the prioritarian is right to reject the ex ante point of view and insist that vaccinations are indeed fairer than more efficient quarantines therefore throw doubt upon the prioritarian's further, and more extreme, rejection of quarantines as unfair even in unvaccinated populations. To sustain this further argument against quarantines, the prioritarian must explain why the pressure away from measuring individual burdens ex ante does not push such assessments all the way to the ex post point of view but instead runs out, as the initial argument assumed, in medias res. And indeed, there is some reason to think that the pressure towards $e x$ post assessments runs out in just this way. ${ }^{54}$ The two arguments that cast taking the ex ante point of view as inconsistent with respecting the separateness of persons do not apply nearly as forcefully to proposals to measure individual burdens in medias res, so that the pressure in favor of the ex post point of view is not inexorable and distributive objections to quarantines that depend upon this intermediate point of view retain some force. At the same time, the distributive case against employing quarantines even in unvacci- nated populations remains, as I suggested earlier, less secure than the distributive case for favoring vaccinations.

The first argument against measuring distributive burdens ex ante observed that this measure produces an even distribution of aggregate burdens (as the suggestion that all efficient quarantines are also fair requires) only when the ex ante point of view comes in very early indeed. And it proposed that any time distributive fairness measures individual burdens in terms of unresolved risks - any time distributive fairness declines to look through risks and instead treats risks themselves as distributively salient - it effectively denies the separateness of persons that prioritarian views of distributive justice seek, precisely, to emphasize. But although this argument clearly presses distributive justice to abandon the extreme ex ante point of view from which all efficient quarantines appear as distributively fair, it is much less clear that the argument requires going all the way to the ex post point of view. Not all differences among persons are equivalent for purposes of distributive justice, and prioritarian distributive justice may perhaps decline to look through certain unresolved risks to their ultimate outcomes without betraying the ideas about the separateness of persons out of which it arises. Although these risks will of course resolve themselves into outcomes that in some literal sense separate the persons whom they befall, this aspect of the separateness of persons does not trigger prioritarian concern. And in such cases, the risks themselves may become distributively salient, which is to say that their expected costs may count as individual burdens for purposes of distributive justice.

The risks that the ex ante approach to infectious disease refuses to look through, for example the risks of exposure to infection mentioned earlier, track distinctions among persons that are politically important and are themselves familiar subjects of pre-theoretical distributive concern. If poor persons or immigrants are disproportionately likely to be exposed to or infected by diseases, then this is in itself obviously unfair. Poverty and immigrant status are attributes that separate some persons from others in intuitively compelling ways, and it will not do for a theory of distributive justice to approach risk in a way that ignores or obscures these distinctions. The $e x$ ante approach to quarantines fails precisely because it measures the burdens of disease at a moment before membership in these more broadly disadvantaged classes is known and therefore inaccurately attributes to all persons an equal, average burden of disease.

But other risks are very different and do not correspond to any familiar subjects of pre-theoretical dis- 
tributive concern. Tall people, for example, may be disproportionately affected by certain head or back injuries, but this difference seems unrelated to any intuitively compelling social or political differences among persons, so that it does not necessarily trigger distributive concern. An approach to distributive justice that measured the burdens of these injuries $e x$ ante, as a risk of injury that falls upon everyone, would fail to recognize the distinction between the tall and the short, to be sure, but it seems unlikely that this is among the differences that prioritarianism wishes to insist upon when it treats the separateness of persons as essential for justice.

Moreover, in extreme cases, differential outcomes do not track any independently identifiable traits, so that it is impossible, ex ante, to associate outcomes with classes of persons at all. These cases involve Acts of God, as one might say, or, more simply, irreducible luck. I do not mean by this that the differential outcomes cannot in principle be explained, at least causally: even the most characteristic cases of Acts of God, for example, a meteor that hits one house rather than another, are susceptible to causal explanation in terms of the relative trajectories of the meteor and house, the conditions when each was created, and so on..$^{55}$ Instead, I mean that these explanations do not include any facts in terms of which we classify persons for any other purposes, so that although taking an $e x$ ante view of such cases - and measuring the distributive burden of irreducible luck by its expected value does aggregate and average what will in the end be different outcomes, it does not gloss over any distinctions between persons that could be identified or even articulated apart from these outcomes. Taking an $e x$ ante approach to irreducible luck seems therefore to deny the separateness of persons only in a reductive, or indeed trivial, sense. And although some theories of distributive justice do take even differences in irreducible luck to be unfair and are therefore inclined to look through the risks such luck involves to ultimate outcomes, the prioritarian concern for the separateness of persons (without more) should not be understood to require it. Certainly the unlucky are not a culturally or politically salient class. ${ }^{56}$

Finally, although the patterns of exposure to infectious disease do track intuitively compelling distinctions between persons (for example the distinction between the rich and poor), the patterns of infection among the exposed plausibly do not, at least not insofar as medical attention is directed evenly at all the exposed. Indeed, by the time quarantines are imposed, all the differences that separate persons in ways that trigger distributive concern may already have resolved themselves. It may be that the only remaining differences at the point of quarantine - the differences concerning infection conditional on exposure - involve irreducible luck, or at least luck that is unrelated to any intuitively compelling differences among persons. In this case, an approach to the distributive fairness of quarantines that measures the burdens of disease in medias res - insisting upon resolving differences in chances of exposure to disease but obscuring differences that concern infection conditional upon exposure and instead according all persons an equal (average) chance of infection - recognizes all the aspects of the separateness of persons that prioritarian distributive fairness insists upon. The approach to quarantines that proceeds in medias res, and measures individual burdens in terms of risks of becoming infected conditional on being exposed, can therefore resist the pressure generated by the first argument for adopting an ex post perspective on individual burdens. ${ }^{57}$

The second argument against treating unresolved risks as distributively salient ex ante observed that all risks eventually resolve themselves into certainties, in which the harms they contemplate are suffered or not, and that this resolution is itself a piece of bad or good fortune that swallows up the initial fortune of facing the risk, so that a person who faces a risk is no differently off, for purposes of distributive justice, from a person who faces the risks' eventual outcome as a certainty all along. But once again, although this argument generally presses distributive justice to look through risks to their resolutions, the argument does not necessarily apply to the case of quarantines. Not every risk is susceptible to the suggestion that its resolution swallows up its imposition for distributive purposes.

Most straightforwardly, this suggestion does not undermine the distributive salience of the unresolved risks involved in deliberate gambles. It certainly is true that the resolution of a deliberate and calculated gamble is itself a piece of good or bad luck, so that only chance separates two gamblers who make identical bets that one wins and the other loses. But distributive fairness properly declines to look through gambles to the ultimate outcomes of the risks that they involve: a losing gambler cannot plausibly be said to have distributive priority over a winning gambler (at least not when the gambles were accepted in equivalent circumstances) and both gamblers are differently lucky from persons who face their ultimate predicaments as certainties from the start. Thus, gamblers who face the same odds are treated equally for purposes of distributive fairness and are preferred and dispreferred over others who face, respectively, shorter and longer odds. ${ }^{58}$ Indeed, it would be unfair, and 
contrary to prioritarian respect for the separateness of persons, for distributive principles to abandon the $e x$ ante approach to gambles and instead look through gambles to their eventual resolutions, giving distributive priority to losing over winning gamblers or even spreading winnings and losses evenly among winners involves as in themselves distributively salient and as involving a distributive burden liquidated by the costs of the vaccinations. And accordingly, if an infection breaks out after vaccinations have been foregone, then the ex post burdens imposed by the outbreak cannot underwrite any distributive claims. ${ }^{64}$

\section{Vaccinations are therefore important to the ethics of quarantines not just because they are themselves fairer than quarantines. Rather, their possibility, by rendering unresolved risks of infection distributively salient and blocking distributive claims based on these risks' resolutions, renders quarantines unfair even as compared to doing nothing to combat the spread of an infection.}

and losers: gamblers choose to be separated by the resolutions of the risks that their gambles involve, and the redistribution across gamblers that follows from looking through gambles to outcomes unfairly undoes this choice to become separated by chance. ${ }^{59}$

Moreover, this approach to risk is not confined to gambles narrowly understood but instead has a much broader application. When persons who face an unresolved risk can (at a reasonable cost) protect themselves against that risk's eventuating, decisions that are not gambles in the orthodox sense may be assimilated to gambles for purposes of distributive fairness. ${ }^{60}$ When such protections in the face of a risk are available, then any further burden suffered in case the risk eventuates is properly assimilated to the deliberate and calculated gamble not to protect against the risk. And distributive fairness, which does not look through the risks involved in gambles, declines to look through risks that may be protected against and treats these risks as in themselves distributively salient. The distributive burden of facing the risks is naturally fixed by the cost of the defending against their eventuation. This cost, one might say, liquidates the burdens of the risks for purposes of distributive justice. ${ }^{61}$

These considerations apply to the risks associated with infectious diseases, at least insofar as the diseases may be combated by vaccinations. ${ }^{62}$ Vaccinations effectively eliminate the risks of infection for those who take advantage of them. Accordingly, insofar as they are available, vaccinations function, as precautions against risks generally function, to render the unresolved risks of the infections that they protect against distributively salient. If vaccinations are possible, then a decision not to employ them involves a deliberate and calculated gamble, and distributive justice declines to look through this gamble to its resolution in assessing individual burdens. ${ }^{63}$ Instead, distributive justice treats the risks that the gamble
Indeed, it would be unfair for persons who had foregone vaccinations to avoid infection by shifting the burdens of a disease onto others, just as it is unfair for losing gamblers to shift their losses onto others. But this is precisely what quarantines do - quarantines enable the as yet unexposed to avoid their gambling losses by shifting these losses onto those who have been exposed, who must bear them in a more concentrated form. Moreover, this shift in the burdens of disease is far from distributively neutral but will tend, instead, to concentrate the losses associated with the gamble to forego vaccinations on those who were initially most at risk of becoming exposed and quarantined and for whom the gamble was from the outset least appealing. ${ }^{65}$ Having taken the gamble of foregoing vaccinations, a society cannot fairly concentrate its losses upon those few of its members who are first exposed to a disease.

Vaccinations are therefore important to the ethics of quarantines not just because they are themselves fairer than quarantines. Rather, their possibility, by rendering unresolved risks of infection distributively salient and blocking distributive claims based on these risks' resolutions, renders quarantines unfair even as compared to doing nothing to combat the spread of an infection. Even when vaccinations are not in fact adopted, their possibility vindicates the approach to quarantines that proceeds in medias res and measures individual burdens in terms of risks of becoming infected conditional on being exposed. This defuses the idea that even if quarantines are less fair than vaccinations, they are at least preferable to allowing an infectious disease to spread unchecked. ${ }^{66}$

The two considerations that explain why prioritarianism rightly rejects measuring individual burdens from the ex ante point of view (from which quarantines appear preferable even to vaccinations) therefore do not in the end require adopting the ex post 
point of view. The accounts of the distributive character of risk that generate the steady pressure towards measuring individual burdens ex post do not push such assessments all the way to the moment of actual infection but instead run out in medias res, roughly as the initial distributive analysis of quarantines supposed. This rejection of the ex post point of view is not quite so secure as the earlier rejection of the ex ante point of view, because it does not follow immediately from the structure of prioritarian distributive thought but instead depends upon additional, and contestable, ideas that say which aspects of the separateness of persons are distributively salient and that identify deliberate and calculated gambles. But insofar as these ideas are plausible, they cast quarantines not only as less fair than vaccinations but also as less fair than doing nothing to combat diseases that arise after vaccinations have been foregone.

\section{Conclusion}

Quarantines are often more efficient than vaccinations at controlling the harms associated with infectious disease, in the sense that they involve a smaller sum of the burdens of disease prevention and the burdens of disease. This is because quarantines may be narrowly targeted at actual outbreaks of disease and the specific persons who are exposed to them, whereas vaccinations must generally be employed in advance of outbreaks of diseases that might never occur and must be applied broadly to persons who are never exposed. But quarantines achieve this efficiency by concentrating their costs upon a few persons, who bear a greater individual burden than anyone would bear under vaccinations, which spread their costs evenly, and therefore thinly, across all persons. Moreover, quarantines compare unfavorably, in respect of the individual burdens borne by the worst-off, even with allowing infectious diseases to spread unchecked. Within-quarantine risks of infection will generally exceed the risks of infection that would prevail in the general population in the absence of quarantines. And quarantines add the direct burdens of confinement to these increased risks of infection.

These observations introduce a tension between the intuitive appeal of quarantines and broader prioritarian instincts and principles concerning distributive fairness and the separateness of persons, which propose that public policy should spread rather than concentrate harms, so that it is most justified to the persons to whom it is least justified. Quarantines violate this requirement when they make the worst-off worse off, and even efficient quarantines are therefore unfair. Vaccinations are certainly fairer than quarantines, and fairness may even counsel allowing an infection to spread unchecked in an unvaccinated population rather than employing quarantines as a second-best alternative when vaccinations have been foregone. Finally, unlike more familiar libertarian concerns about quarantines, these egalitarian anxieties are not just artefacts of abuses in quarantine administration but instead reflect quarantines' genetic structure.

The case for quarantines may, of course, be revived. Most narrowly, the distributive argument against quarantines, and in particular the argument against quarantines as a second-best policy when vaccinations have been foregone, turns on sticky and contentious propositions about the distributive salience of various kinds of risk. These attitudes towards risk are necessary to sustain the in medias res assessments of individual burdens on which the distributive argument depends, and they might be rejected even within prioritarian approaches to fairness. Somewhat more broadly, quarantine advocates may attack the prioritarian conception of distributive fairness itself. They may claim that the prioritarian conception unfairly privileges the worse-off, perhaps by arguing that the distinction between persons is overdrawn in the prioritarian conception or that some elements of
Medical quarantines appear, on reflection, to be unjust, and any serious argument in favor of quarantines must take up, as the current debate does not, the questions of distributive fairness that I have set out here.

the marginalist approach can survive even in the teeth of the distinction between persons. And finally, and most broadly, quarantine enthusiasts might propose that fairness, even rightly understood, should play a smaller role in all-things-considered practical deliberations than the argument against quarantines supposes, and in particular that gains to efficiency, when they are substantial, should outweigh some measure of unfairness. ${ }^{67}$

Each of these responses has some persuasive power, although just how much will vary from case to case. The third, about efficiency, will in some cases be particularly hard to resist: when the numbers at stake get large enough, it will become hard to insist that aggregates don't count; and even when vaccinations have been improperly foregone, it will be especially hard to say that quarantines that might dramatically reduce 
the number of infections must be abandoned in favor of doing nothing to combat a disease. But each response also suffers drawbacks, and none more so that the third, about efficiency, which just overwhelms rather than answers the charge that quarantines are unfair. It is not easy to say how large efficiency gains must get before they become overpowering in this way: certainly we accept substantial inefficiencies in the service of distributive concerns in other circumstances, most notably in connection with economic redistribution, and this makes it plausible that distributive concerns might justify similar inefficiencies in disease control. Moreover, even when the numbers at stake are so large that the pressure in favor of quarantines becomes truly irresistible, the distributive claims of the persons upon whom quarantines concentrate their burdens do not disappear and must be acknowledged in some way, even if they should not be simply granted. Just how to acknowledge them of course remains an open question. ${ }^{68}$

All these complications are entirely consistent with my initial ambition in taking up the question of quarantines and distributive justice. Instead of defending any ethical conclusion, I have introduced and explained new ethical questions. And instead proposing specific policies, I have sought general principles under which such policies might be developed. These efforts show that the case for quarantines cannot rest, as it has done, on the observation that quarantines control infectious diseases more efficiently than alternative methods. Medical quarantines appear, on reflection, to be unjust, and any serious argument in favor of quarantines must take up, as the current debate does not, the questions of distributive fairness that I have set out here.

\section{Acknowledgements}

I would like to thank Steven Latham, Marc Lipsitch, Arti Rai, and Victoria Sutton for comments on earlier versions and Jane Gao, Dan Korobkin, and Eric Rosenstock for outstanding research assistance.

\section{References}

1. Both themes are illustrated, for example, by the quarantines imposed during the 1892 New York typhus and cholera epidemics: the conditions in the East River lazaretto were horrific and the administration of the quarantines engaged nativist sentiments. See H. Markel, Quarantine! East European Jewish Immigrants and the Nere York City Epidemics of 1892 (Baltimore, MD: Johns Hopkins University Press, 1997).

Moreover, the connection between quarantines and cruel prejudice is not confined to the passing terror associated with epidemics but also arises in more normal circumstances. For example, the Contagious Diseases Acts (in force in Britain from the 1860 s to the 1880s) responded to the venereal diseases that had become endemic in Victorian society by allowing arbitrary and degrading confinements of women suspected of prostitution. Men who spread the diseases, including in particular sailors and soldiers, were not subject to the laws, which entrenched discrim- inatory ideas about gender as part of the steady state of Victorian public policy. See A. N. Wilson, The Victorians (London: Hutchinson, 2003): at 308-10.

2. The harm principle that underwrites the libertarian's concern for civil rights, after all, contains a grant of power as well as a restriction, as Mill's original formulation of the principle made plain: "the only purpose for which power can be rightfully exercised over any member of a civilised community, against his will, is to prevent harm to others," J. S. Mill, On Liberty, (1863) reprinted in Utilitarianism, Liberty, and Representative Government (Everyman Library ed., New York: Dutton, 1951): at 95-96. The law, moreover, reaches the same conclusion, and indeed for the same reason. Thus the United States Supreme Court has observed that "real liberty for all could not exist under the operation of a principle which recognizes the right of each individual person to use his own, whether in respect of his person or his property, regardless of the injury that may be done to others." Jacobson v. Massachusetts, 197 U.S. 11, 26 (1905). And it has recognized, on this basis, "the authority of a State to enact quarantine laws" under a "police power" that embraces "such reasonable regulations... as will protect the public health and the public safety." Id. at 25 .

Legal challenges to quarantines therefore cannot hope to succeed by attacking the quarantine power in itself but must instead attack some feature of quarantine administration which, as the Supreme Court has also recognized, may proceed "by regulations so arbitrary and oppressive in particular cases as to justify the interference of the courts to prevent wrong and oppression." Id. at 38. An example of a successful attack of this sort appears in Greene v. Edwards, 263 S.E.2d 661 (W. Va. 1980), in which a person quarantined for tuberculosis successfully challenged an administrative process that confined him without providing, among other things, adequate access to counsel and an opportunity to cross-examine witnesses against him at the quarantine hearing.

3. A recent practical effort to balance these concerns against each other appears in the Model State Emergency Health Powers Act (2001), available at <http://www.publichealthlaw.net/MSEHPA/MSEHPA2.pdf (last visited May 3, 2005). The specific accommodation represented by the Act has been criticized by some civil libertarians. See, e.g., T. May, "Political Authority in a Bioterror Emergency," Journal of Law Medicine \& Ethics 32 (2004): 159163, at 161 (2004); W. E. Parmet, "Quarantine Redux: Bioterrorism, AIDS, and the Curtailment of Individual Liberty in the Name of Public Health," Health Matrix 13 (2003): 85-116; G. J. Annas, "Blinded by Bioterrorism: Public Health and Liberty in the 21st Century," Health Matrix 13 (2003): 33-70, at 46-63; A. Goldstein, “Mr. Quarantine Meet Miss Liberty," Time, April 18, 2002, at 19.

4. Here I am using the term "quarantine" in its generic sense to refer to the broad class of practices that contain infectious diseases by segregating possible carriers from the general population. A narrow usage distinguishes isolation - which segregates only those who are actually ill - from quarantines proper - which segregate exposed persons within a community whether they are ill or not - from cordons sanitaire - which segregate entire communities (typically cities or towns) from the outside world.

5. Other diseases - including many gastrointestinal diseases and most sexually transmitted diseases - may be controlled by blocking the specific pathways through which the infections spread, for example by public and private sanitary practices such as good sewers and safe sex. Many of the comparisons that I draw between quarantines and vaccinations may also be drawn between quarantines and sanitation, although I shall not develop these points here.

6. One prominent example is the proposal to respond to a smallpox outbreak by a combination of "isolation of infected individuals, surveillance of contacts, and a focused selective vaccination program." D. A. Henderson, et al., "Consensus Statement, Smallpox as a Biological Weapon: Medical and Public Health Management," JAMA 281 (1999): 2127-2137, at 2136-37 (1999). I shall return to this proposal in later endnotes.

7. "Primary active immunization develops more slowly than the 
incubation period for most infections and must therefore be induced prior to exposure to the etiologic agent." D. P. Stites, A. I. Terr, and T. G. Parslow, Basic and Clinical Immunology 8th ed.(Norwalk, CT: Appleton \& Lange, 1994) at 718. The head start needed by a vaccine may be substantial. The Ebola vaccine, for example, takes four weeks to confer immunity. See T. Clarke and J. Knight, "Fast Vaccine Offers Hope in Battle with Ebola," Nature 424 (2003): 602. See also, N. J. Sullivan, T. W. Geisbert, and J. B. Geisbert, et al., "Accelerated Vaccination for Ebola Virus Haemorrhagic Fever in Non-Human Primates," Nature 424 (2003): 681-84 (2003). Earlier Ebola vaccines took six months and several boosters to confer immunity.

8. If a disease spreads sufficiently slowly and a vaccine against it confers immunity sufficiently quickly, it may be possible to contain the disease through post-outbreak vaccinations administered broadly, including to persons who have not been exposed. In such cases, vaccines are less inefficient than the main text contemplates and commensurately more appealing. This possibility only strengthens the case for vaccinations presented in the main text.

9. This means that the inefficiency of vaccinations increases as the chances of an outbreak decrease. It is therefore unsurprising that vaccinations are most prominently employed to protect against endemic diseases, for example the familiar childhood diseases, whose outbreak is virtually certain.

10. This means that the inefficiency of vaccinations increases as the infectiousness of a disease decreases. It is therefore unsurprising that vaccinations are most prominently employed to protect against diseases, including again the familiar childhood diseases, that are extremely infectious.

11. When vaccinations are effective even after exposure to a disease has occurred, the balance may change. The proposed measures for combating an outbreak of smallpox that I discussed at note 6 , supra, provide a case in point.

The smallpox vaccine provides some protection against infection and reduces the severity of infection even if administered after first exposure to the disease. Henderson, supra note 6 , at 2132. This may make it possible to contain smallpox through narrowly targeted post-exposure vaccinations (coupled with quarantines). And indeed, the Consensus Statement on combating smallpox adopts precisely such a strategy of "ring vaccination."

Of course, the fact that such a strategy is medically possible does not guarantee that it is best in practice. Even smallpox vaccine is effective only if administered promptly after exposure, and it may happen that, especially in the confusion and panic of an outbreak, the pattern of exposure outstrips the vaccinations capacity to keep up (even when supported by quarantines), so that post-exposure vaccinations cannot practicably be administered in time to stop an epidemic. In this case, controlling the disease once again demands mass pre-exposure vaccinations. See, e.g., E. H. Kaplan, D. L. Craft, and L. M. Wein, "Emergency Response to a Smallpox Attack: The Case for Mass Vaccinations," Proceedings of the National Academy of Sciences 99 (2002): 10935 (arguing that mass vaccinations including of unexposed persons at the first sign of an outbreak involve lower overall costs than vaccinations that trace the path of an outbreak and more narrowly target exposed persons); A. S. Fauci, "Smallpox Vaccination Policy - The Need for Dialogue," N. Eng. J. Med. 346 (2002): 1319 (elaborating the advantages of voluntary mass preoutbreak vaccination against smallpox).

12. Note that these numbers reflect a within-quarantine rate of transmission of the infection that exceeds the rate of transmission in the general population in the absence of a quarantine. This is a reasonable assumption, because quarantines will typically confine persons who have merely been exposed in close proximity with persons who are already infected and therefore impose increased risks of infection upon persons who enter the quarantines free of the disease. This assumption will play a prominent role later in the argument, and I take it up in greater detail there.

13. A one in five chance of suffering two-and-a-half million infec- tions imposes an expected aggregate burden of 500,000 infections.

14. Ten million certain vaccinations at a per-vaccination burden equivalent to $1 / 40$ the burden of infection impose an aggregate burden equivalent to 250,000 infections.

15. A one in five chance of confining one million persons to a quarantine in which 650,000 will become infected and all will face a burden of confinement equivalent to $1 / 10$ the burden of infection imposes an expected aggregate burden equivalent to 150,000 infections.

16. The patterns of infection (both within and without the quarantine) are characterized theoretically, in the epidemiological literature, in terms of a disease's basic reproductive rate, which is the average number of secondary infections produced when one infected individual is introduced into a homogeneous host population in which everyone is susceptible. See R. Anderson and R. May, Infectious Diseases of Humans (New York, Oxford: Oxford University Press, 1991): at 17 . Where the basic reproductive rate is $R_{O}$, the proportion of a homogeneous wholly susceptible population eventually infected by a disease is $p=1-e^{\left(R_{0} p\right)} . R_{0}$ depends both on the biology of a disease - specifically the length of the disease's infectious period and the chance that contacts between infectious and susceptible persons will cause new infections - and on the structure of the society in which the disease appears - specifically on the number and intimacy of contacts between infectious and susceptible persons. Changing social behavior to increase (decrease) the number and intimacy of these contacts therefore increases (decreases) a disease's $\boldsymbol{R}_{0}$, even in a wholly susceptible population, and therefore also increases (decreases) $p$. The higher within-quarantine proportion of infected persons in the example reflects an assumption (taken up in greater detail in note 19, infra, and accompanying text) that contacts within quarantines are more frequent and intimate than in the general population in the absence of quarantines. Finally, $p$ is of course affected as well by the percentage of a population that brings pre-existing disease resistance to an outbreak. The patterns of infection in the example roughly resemble the patterns of disease in Europe during the Black Death of 1347-48 and in London during Great Plague of 166566. See S. Scott and C. Duncan, Biology of Plagues: Evidence from Historical Populations (New York: Cambridge University Press, 2001): at 87,217 . They are also roughly consistent with measures of $R_{o}$ recently estimated for Ebola in Congo and Uganda. See G. Chowell et al., "The Basic Reproductive Number of Ebola and the Effects of Public Health Measures: the Case of Congo and Uganda," Journal of Theoretical Biology 229 (2004): $119-26$

The probability of an outbreak and the relative burdens of infection, confinement to quarantine, and vaccination are brute facts, by contrast, and may not be given any theoretical development. I have tried to set them at intuitively plausible levels.

17. The main text glosses over the fact that vaccinations can sometimes cause extremely severe (and even fatal) reactions in some persons, including reactions quite as severe as the symptoms of the diseases they protect against. But such reactions are extremely rare, so that they will often be much less numerous than the cases expected at the hands of the diseases if vaccinations are foregone and quarantines are employed in their stead. This will be true even with respect to fatal reactions to vaccinations against non-fatal diseases, because even diseases that are not ordinarily fatal do sometimes kill, when they beset the old or the young or when complications arise, and fatal reactions to vaccinations are generally so rare that they are outnumbered even by these exceptional cases. Fatal reactions to vaccinations therefore often should not figure prominently in the efficiency analysis of disease control. Instead, the inefficiency of vaccinations is principally caused not by the very, very few persons who suffer severe harms from being vaccinated but rather by the many, many persons who suffer much smaller harms. These small harms are so common that they come, in aggregate, to exceed the fewer but individually greater harms associated with quarantines. 
But fatal reactions to vaccinations might nevertheless matter to the distributive analysis upon which I am focusing here, and it might seem, therefore, that it is mistaken for me to disregard them in the main presentation of my argument. In fact, however, the few fatal reactions to vaccinations are overbalanced, even from a distributive point of view, by the many more fatalities to be expected at the hands of disease in case vaccinations are foregone. The reason for this will become plain as the distributive argument develops, and it is set out in note 52 , infra.

18. The phrase comes from Defoe, whose account of the Plague of London reports that the practice of "confining the Sound in the same House with the Sick, was counted very terrible," D. Defoe, A Journal of the Plague Year (1772) Cynthia Wall ed., (New York: Penguin, 2003): at 150, and that "many people perished in these miserable Confinements, which "tis reasonable to believe, would not have been distemper'd if they had had Liberty." Id. at $\mathbf{4 8}$. Defoe's belief is confirmed by modern accounts of the Plague, which conclude that "certainly, the practice of shutting up a family in their house when plague first struck must have increased the inter-household contact rate." Scott and Duncan, supra note 16 , at 226 .

19. Recall that $R_{O}$, and consequently also $p$, depend not just on the biology of a disease but also on social factors concerning the population within which the disease arises, in particular on the frequency and intimacy of contacts between infectious and susceptible persons. Because quarantines confine the sound and sick at close quarters, such contacts will inevitably be more frequent and more intimate within quarantines than without them, and $R_{O}$ and $p$ within quarantines will be commensurately higher, as the example supposes.

Moreover, this theoretical prediction is supported by empirical reports about disease transmission in close quarters that resemble mass quarantines. Thus the Centers for Disease Control reports that "historically, placement in quarantine has been associated with increased disease transmission." See Centers for Disease Control, Supplement D: Community Containment Measures, Including Non-Hospital Isolation and Quarantine, in Public Health Guidance for Community-Level Preparedness and Response to Severe Acute Respiratory Syndrome (SARS) Version 2, 29 [hereinafter CDC Guidelines] (Jananuary 8, 2004), available at <http://www.cdc.gov/ncidod/ sars/guidance/d/pdf/d.pdf> (last visited May 3, 2005). And in the recent SARS epidemic 94 percent of the cases reported in Taiwan occurred through transmission in hospital wards. See "Health Chief Says 94\% of SARS Cases Result of Hospital Infections," Taiwan Headlines (May 20, 2003), available at <http://www.taiwanheadlines.gov.tw/20030520/20030520sl.h tml $>$ (last visited May 3, 2005). The same effects appeared in Hong Kong and Singapore. See World Health Organization Update 28-Affected Areas, Status of SARS Outbreaks in Individual Countries (Apr. 12, 2003), available at< http://www. who.int/csr/sarsarchive/2003_04_12/en/> (last visited May 3, 2005). Similarly, a review of smallpox infections in Europe between 1950 and 1971 shows that of the 680 reported cases, 339 contracted the disease in hospitals. See T. M. Mack, "Smallpox in Europe, 1950-1971," Journal of Infectious Diseases 125 (1972): 161-169. Finally, the rate of tuberculosis in the New York State Prison population is 156.2 cases per 100,000 persons, which significantly exceeds the rate in the United States overall, which is 10.4 cases per 100,000 persons. See S. E. Valway et al., "Multidrug-resistant Tuberculosis in the New York State Prison System 1990-1991," Joumal of Infectious Disecises 170 (1994): 151.

These observations do not apply to all diseases, of course. Most notably, $R_{O}$ may be high enough in the non-quarantine state so that the proportion of infected persons in the general population approaches 100 percent, in which case the proportion of infected persons within quarantines cannot be higher.

20. See CDC Guidelines, supra note 19 , at 29.

21. More than 30 states forcibly detained tuberculosis patients in the years following World War II, for example, either in locked hospital wards or in prisons. See B. H. Levner, "Tuberculosis in Seattle, 1949-1973: Balancing Pubic Health and Civil Liberties,"
Western Journal of Medicine 171 (1999): 44-45.

22. One model of a large smallpox attack in a population of 10 million persons, for example, concludes that controlling the attack through post-exposure vaccinations and quarantines would require quarantining 59,000 symptomatic cases. See Kaplan, Craft, and Wein, supra note 11, at 10935-36.

23. Here it is of course critical that vaccinations are not generally effective unless administered prior to exposure to the diseases that they protect against, so that within-quarantine rates of infection generally cannot be controlled simply by vaccinating those who have been quarantined.

24. Some of these burdens may perhaps be compensated, even if they cannot be eliminated. But problems of valuation and perhaps even incommensurability will render any compensation that is offered imperfect at best and at worst inadequate. Moreover, not all the burdens associated with quarantines can be compensated. Most starkly, when a disease is fatal, the infections caused or allowed by quarantines cannot be compensated.

25 . The numbers in the example make the simplifying assumption that only a few quarantined persons are actually infected when the quarantine is imposed and that virtually all quarantined persons who eventually suffer the disease become infected within the quarantine. This assumption is necessary for equating the within-quarantine risks of infection with the ratio of total within-quarantine infections to quarantine size. The assumption fits with the perfectly effective quarantine that the example involves, which must sweep broadly enough so that no cases arise without it and must therefore sweep up many persons who have been exposed but not infected or have not even been exposed.

26. A secondary effect is worth mentioning in the margin. When vaccination policies fail to immunize everyone or fail to confer total immunity, some persons may become infected even under a vaccination regime. Vaccinations, in such cases, will reduce but not eliminate infections. Moreover, it may happen that the weaker force of infections in an imperfectly vaccinated population causes the (fewer) persons who are infected to catch the infection at older ages and therefore to become more seriously ill than the younger persons who would otherwise be infected. See Anderson and May, supra note 16, at 99. In this case, the greatest individual burdens may be greatest under a vaccination regime. I do not take up this unlikely possibility here.

27. It is tempting to avoid these questions of fairness altogether, and to sidestep the entire line of argument that I develop, by emphasizing that persons who have been exposed to an infectious disease themselves become agents of its spread and this way appear, to the as yet unexposed, as aggressors, albeit innocent ones. This observation suggests conceiving of quarantines as a means of self-defense by the unexposed or of other-defense undertaken on behalf of the unexposed. And when quarantines are conceived of in this way, the problems of distributive fairness upon which I focus appear less pressing, because the justification of defensive measures adopted against even innocent aggressors does not depend upon such distributive considerations, at least not any straightforward way.

But this line of argument neglects the fact that in the cases of quarantine at issue, the defensive measures to which the argument refers are adopted not by private persons but by the state. Although I have no set views on the matter, I find it plausible to say that a private person may protect herself against an infectious disease by denying an exposed person access to her infection-free enclave even where such defensive action subjects the innocent aggressor to a greater risk of infection than it defends against. I might perhaps also be persuaded that a private person may defend others in analogous cases. But the state is in a very different position in such cases, because its quarantines are supported not just by force, but by authority: the state's quarantines purport to subject exposed persons to an obligation to respect them. This obligation can be sustained only if the state grants all its citizens equal concern, which requires that the state not unjustly prefer some citizens over others. And this returns the argument to the issues of distributive fairness developed in the 
main text. I wish to thank Alec Walen for emphasizing the need to address the relationship between quarantines and selfdefense.

28. See Euripides, Iphigenia at Tauris and Iphigenia at Aulis. The planned sacrifice never actually occurred, because Iphigenia was miraculously transported to Tuaris and an animal sent in her place.

29. This concern for fairness finds an interesting expression in the Christian adaptation of religious sacrifice, in which Christ died on the cross to relieve humanity of the burden of it sins: the conceit of Christ's divinity, which is necessary for the crucifixion's effectiveness, at once eliminates any ordinary concern for the fair treatment of the sacrificial offering.

30 . The two cases are not identical in all respects, and one difference between them is that sacrifices literally use their victims in the service of others whereas quarantines do not (so that the sacrificial victims become the means whereby the ends of others are served, whereas quarantined persons do not). This may underwrite an independent objection to sacrifices, based on Kantian ideas about the inviolability of the person. See, e.g., F. Kamm, Morality, Mortality: Rights, Duties, and Status, vol. 2 (New York: Oxford University Press,1996): at 172-206.

The two objections are distinct and should not be confused. The inviolability objection applies even when the person who is used as a means suffers an individual burden that is not greater, and may even be smaller, than the individual burdens faced by the persons whom she is used to save. And the distributive objection applies, as the next example in the main text illustrates, even when there is no suggestion of literally using one person to serve another.

31. Every economy of course also contains unproductive persons who are responsible for their state - who have squandered their talents, who refuse to exploit their talents, or even who have simply failed to develop their talents. The observations in the main text do not take a position on the complex of questions involved in separating the two classes of unproductive persons, save perhaps insofar as they assume (plausibly, I think) that the class of persons who are not responsible for being unproductive is not empty.

32. Taxes, as economists say, create dead-weight loss.

33. At least in an otherwise Pareto perfect economy.

34. See J. Rawls, A Theory of Justice (Cambridge, MA: Belknap Press of Harvard University Press, 1971): at 75.

35. Notice that although efficient markets sacrifice the unproductive in the service of efficiency, there is no suggestion that they use the unproductive literally as means, so that the ideas concerning human inviolability mentioned in note 30 , supra, cannot account for our intuitive opposition to unfettered free markets. Indeed, if these ideas apply at all to the economic case, then they apply on the other side of the argument, as in Robert Nozick's suggestion that redistributive taxation drafts the productive into the service of the unproductive. See R. Nozick, Anarchy, State, and Utopia (New York: Basic Books, 1974): at 172, 228-29. I do not accept this suggestion, for reasons that I have set out in D. Markovits, "How Much Redistribution Should There Be?" Yale Law Journal 112 (2003): 2291-2329, at 23252326. The merits of this argument do not matter here, however, although it is worth mention that our distributive intuitions against minimizing aggregate burdens by concentrating them seem able to stand up even to our Kantian intuitions concerning the inviolability of persons.

36. Finally, ultimately, overall.

37. The reference to a utilitarian in this context is natural, since the utilitarian concern to maximize aggregate well-being broadly understood presents the most historically prominent general foundation for the impulse to minimize aggregate suffering from disease that underwrites quarantines' intuitive appeal. The dictum, incidentally, is attributed to Bentham by Mill. See J. S. Mill, Utilitarianism, George Sher ed. (Indianapolis, IN: Hackett Publishing Co.., 1979): at 60. Although it is commonly thought that Bentham never actually adopted this form of words himself - and Mill certainly provides no citation -
Bentham in fact did utter almost the exact phrase Mill reports, saying that "every individual in the country tells for one; no individual for more than one." See J. Bentham, "Rational of Judicial Evidence," in J. Bowring, ed., The Works of Jeremy Bentham, vol. 7 (Edinburgh and London: W. Tait, 1843): vol. 6: 201-585 at 334, and vol. 7: 1-644. I would like to thank Gerald Postema for pointing this reference out to me.

38. Rawls, supra note 34, at 27.

39. The marginalist conception of equality may have secondary or indirect distributive implications, as in the familiar utilitarian suggestion that, in light of the diminishing marginal utility of money, equal distributions of a fixed total of wealth will tend to produce greater total well-being than unequal distributions. But the utilitarian concern for distributions is necessarily incidental and contingent only - there is of course no diminishing marginal utility of well-being, and utilitarians will accept unequal distributions of well-being whenever such inequalities contribute to increases in total well-being. This distinction is practically important, moreover, because the utilitarian concern for equality even of wealth runs out when the diminishing marginal utility of wealth does not apply or is outweighed by other considerations. Utilitarians will not, for example, support redistribution in favor of persons whose handicaps render them inefficient converters of wealth into well-being (so that their marginal utility of wealth is low everywhere on the scale).

40. This way of thinking was brought to prominence in modern moral philosophy by G. E. M. Anscombe and J. Taurek. See G. E. M. Anscombe, "Who is Wronged?" The Oxford Review 5 (1967): 16-17 and J. Taurek, "Should the Numbers Count?" Philosophy and Public Affairs 6 (1977): 293-316.

41. The argument involves a second assumption also, which bears mention in the margin, namely that outbreaks of infectious disease are distributively isolated events.

If a population of persons foreseeably faces repeated threats under conditions in which it will be impossible to save everyone who is threatened, then prioritarian principles may approve of policies that respond to each threat by minimizing aggregate harm even if this does not minimize the greatest individual harm from that threat that any person must bear. In such cases, the scope of distributive concern may plausibly be set not at the individual threat but at the overall sequence of threats. And a policy of responding to each threat by minimizing the aggregate harm caused by that threat may, over the long run, minimizing the greatest individual harm caused by the series of threats, even if it does not minimize the greatest individual harm caused by each threat in the series. Something like this argument from repetition may be used to justify common practices of triage in hospitals and on the battlefield. Even if each case of triage fails to minimize the greatest individual burden faced by the persons it assesses, these persons will all be subject to triage many times, and the general practice of triage may minimize the greatest individual burden any of them faces over the course of his life.

This argument cannot, however, be plausibly applied to medical quarantines, at least not under current conditions. It requires that the harm to which triage is applied be a repeat event, and outbreaks of infectious disease of the type to trigger quarantines happily remain exceptional, so that the average person will not face them many times over in her life. Moreover, the argument applies only if, in addition to being repeated, the threats arrange themselves in such a way that the benefits and costs of triage are distributed roughly evenly across the threatened population over time. And even if epidemics do become more common than they are today, it seems most unlikely that the benefits and costs of quarantines will be distributed in this even way. It is much more likely, in actual, non-ideal societies, that the differences in underlying chances of exposure to disease are so great and so stable that repeat quarantines do not spread burdens and benefits at all but instead exacerbate the concentration of burdens associated with each individual quarantine, because the same persons turn out to be exposed, and quarantined, again and again. And it will almost certainly be true, in actual, non-ideal societies, that differences in underlying 
chances of exposure to infectious diseases are sufficiently great, and sufficiently stable, so that quarantine policies that minimize the overall incidence of disease will, even over the long run, in some measure increase the incidence of disease among those who are already most likely to be exposed. This is vividly illustrated in Markel's account of the 1892 New York typhus and cholera epidemics and the quarantines that followed, in which both infection and quarantine fell disproportionately upon poor, immigrant and Jewish populations. See Markel, supra note 1. Even if, contrary to fact, the quarantines had been untouched by nativist and discriminatory animus and had been humanely administered, this disproportionate incidence would have made them unfair.

42. This assumes, of course, that the risks of exposure, quarantine, and infection fall equally on all persons. I take up this assumption, and the weakness it introduces into the case for measuring individual burdens ex ante, in a moment.

43. This is entailed by the assumption that the quarantines are more efficient than the vaccinations.

44. In the extreme case, in which the identities of the persons who will be exposed and quarantined are fixed in advance of any actual outbreak of disease, the pattern of individual ex ante burdens associated with quarantines will precisely match the pattern of individual burdens measured in medias res. In this case, the priortarian concern that quarantines are unfair will apply identically from the ex ante point of view as at the moment of the quarantine decision.

45. Here it is instructive to note the contrast between the use of the ex ante point of view in the argument that quarantines satisfy prioritarian distributive principles and Rawls's use of the ex ante point of view in the Original Position. Although the Veil of Ignorance obscures all facts that distinguish persons from one another in the real world, so that the parties to the Original Position cannot know the individual circumstances they will experience once the Veil is lifted, it does not deindividuate outcomes in the manner that I have criticized. The parties behind the Veil do not know just the aggregate benefits and burdens that will arise in the society that they will enter when the Veil is lifted but rather the distinct parcels of benefits and burdens that all individual persons in that society will possess. Moreover, the parties reason as if the worst of these parcels will be individually theirs. In stark contract to the argument that I have criticized, the $e x$ ante point of view, in Rawls's hands, emphasizes rather than obscures the differences among persons that will arise ex post.

46. T. M. Scanlon, What We Owe to Each Other (Cambridge, MA: Harvard, 1998): at 233. Scanlon makes this observation in the course of asking whether prioritarianism allows a person who must choose between saving a larger and a smaller group of persons from identical individual harms to save the larger group. If the ex ante point of view is appropriate and risk is distributively salient, then prioritarianism seems to require choosing which group to save by tossing a coin, because this procedure, which leaves each person with a $1 / 2$ chance of being saved, minimizes the maximum individual risk, the maximum ex ante burden, that any person faces. Although some prioritarians have proposed tossing a coin in such a case, see Taurek, supra note 40 , at 306-10, Scanlon rejects such procedures for the reason given in the main text. It is a mistake, he says, to suppose that an appeal to chance serves prioritarian fairness on the grounds that "whoever loses out...has at least been given a chance of being saved." Scanlon, at 233. Scanlon insists, instead, that "the ultimate stakcs for the people affected are the same" under the coin-toss as under alternative decision rules that save one group for certain: "some will suffer severe harm, the others will be saved." Id. at 233.

Scanlon's discussion, incidentally, addresses not a coin-toss but rather a lottery in which each group's chance of being saved is weighted by its size. His official position is to reject the cointoss in favor of this lottery on the ground that the coin-toss gives the same overall chances of being saved to the smaller as to the larger group and therefore accords the members of the smaller group a greater per-person weight in the decision rule than the members of the larger group, which violates the basic requirement of "treat[ing] the claims of each person who could be saved as having the same moral force." Id. at 232. But if risks are distributively salient, so that a person with a smaller chance of being saved is worse off than a person with a bigger chance of being saved, then the coin-toss does not accord the members of the smaller group a greater per-person weight in the decision process than the members of the larger group. Instead, the cointoss treats all persons equally by according those facing a greater harm (a smaller chance of being saved) greater weight than those facing a lesser harm (a bigger chance of being saved), which is precisely what the prioritarian view of distributive fairness requires. If risk is distributively salient, then the weighted lottery, especially when the groups, and hence the weights, have very different sizes, unjustifiably prefers the members of the larger group by allowing their individually lesser burdens to outweigh the individually greater burdens of the members of the smaller group. Accordingly, as these observations emphasize, Scanlon's discussion of the weighted lottery provides no independent reason for rejecting the coin-toss. Everything depends on the claim that unrealized risk cannot be distributively salient.

47. This way of putting the point recalls Stephen Perry's argument that (at least insofar as the underlying outcomes proceed deterministically) a risk of loss, rather than being itself a harm, is merely a reflection of epistemic limitations concerning knowledge of certain harms. See S. Perry, "Risk, Harm, and Responsibility," in Philosophical Foundations of Tort Law, D. Owen ed., (New York: Oxford University Press, 1995): at 321-46 Perry argues, on the basis of this claim, that risk itself should not be actionable in tort, that is, that risk is not salient for purposes of corrective justice. And indeed, it seems that treating unresolved risks as harms acquiesces in our epistemic limitations in an unjustified way.

48. Indeed, it is critical to prioritarian distributive principles that persons maintain a coherent identity across their many experiences and that this identity, and not just the individual experiences, is a proper subject of moral concern. One line of attack against the prioritarian view of distributive justice, most prominently presented by Derek Parfit, seeks to cast doubt on precisely this claim about personal identity. See D. Parfit, Reasons and Persons (New York: Oxford University Press, 1984).

49. These considerations, incidentally, also have implications for the management of non-communicable diseases (such as anthrax), for which the question of quarantines obviously does not arise. When such diseases are unlikely to affect many people, the aggregate costs of vaccinations (which must be administered generally) may exceed the aggregate costs of the relatively few infections that the vaccinations would prevent. But fairness may require making vaccinations available in such cases even though they are inefficient. The greatest individual costs of suffering the diseases may exceed the greatest individual costs of the vaccinations that protect against them. And although this relation between individual burdens would be reversed if the burdens were assessed ex ante, so that the costs of contracting the diseases were discounted by the unlikelihood of doing so, the arguments in the main text explain why distributive arguments may not assess individual burdens from this $e x$ ante point of view. Some people may of course decline the vaccinations they are offered (including for the reason that their expected burdens exceed their expected benefits). Those who decline vaccinations and then become infected cannot, for reasons elaborated below, make distributive claims based on the burdens of their infections.

50. Many prioritarians, for example T. M. Scanlon, do in fact accept this conclusion. See Scanlon, supra note 46 , at 229-41. A notable exception to this approach is G.E.M. Anscombe's suggestion that although "because they are more" is a perfectly intelligible reason for saving the larger group, "it doesn't follow that a man acts badly if he doesn't make it his reason." Anscombe, supra note 40, at 16-7. For Anscombe, either course in such a case - saving the smaller or the larger group - "seems O.K." Id. at 16 . 
51. This account of the prioritarian's reasoning in saving the larger number, and the sense in which it does without reference to aggregate burdens, appears in R. Kumar, "Contractualism on Saving the Many," Analysis 61 (2001): 165.

52. Note that this argument explains the claim, made in note 17 , that the prioritarian distributive preference for vaccinations over quarantines is not undermined by the fact that vaccinations cause a small number of individual harms that are as severe as the diseases they protect against. These individual harms are counterbalanced, one-by-one, by the more numerous and equally individually severe harms caused by the diseases in case vaccinations are foregone, until the distributive objections to vaccinations are all eliminated while distributive objections to quarantines remain in force.

53. In the case of quarantines, these two groups will typically overlap - some of those who will be infected under a quarantine will also be infected without a quarantine. This can only strengthened the case for quarantines. The persons who will be infected in every event and who therefore cannot be saved may be taken out of the moral calculus altogether. And doing so skews the ratio of numbers saved still further in favor of quarantines.

54. I am in fact quite generally dubious of sweeping suggestions that distributive fairness should always adopt the $e x$ post perspective and look through risks to their resolutions, which seem to me insufficiently sensitive to differences among risks that are important from the distributive point of view. Prioritarian distributive fairness belongs to a broad constellation of ideas that emphasize the individuality and dignity of persons, and other ideas in this constellation may require persons to take ownership of unresolved risks (even for distributive purposes) rather than await their eventual resolution. Indeed, I have argued elsewhere that the very idea of individual personal agency requires that distributive fairness take an $e x$ ante view of at least some risks. See Markovits, supra note 35, at 2291

Others have also made claims for the moral relevance of unresolved risks. Claire Finkelstein, for example, argues that for purposes of corrective justice, the imposition of unresolved risk quite generally in itself harms persons who must bear the risk and presents a catalogue of cases in which tort law and criminal law approach unresolved risks in this way. See C. Finkelstein, "Is Risk a Harm?" University of Pennsylvania Law Review 151 (2003): 963-1001, at 965, 975-90.

55. Determinism, on one understanding, is the view that such causal explanations, going arbitrarily far back, are always possible.

56. There may perhaps be reasons besides justice for looking through even irreducible risks to their ultimate outcomes at least in some measure, including most notably that persons are risk averse and therefore value protection against the outcomes, even $e x$ ante, at more than their actuarial burden.

Insurance and distributive justice take overlapping attitudes towards risk, therefore, but the two attitudes should not be confused. In particular, the insurance rationale does not depend upon any ideas involving the separateness of persons, and it therefore does not run out in cases (such as the case of irreducible luck) to which these ideas do not apply. And conversely, the distributive rationale does not depend upon preferences over risk, and it therefore does not run out in cases in which these attitudes do not exist.

57. Notice that these reflections fix the point in time at which in medias res assessments of individual burdens may properly be made by connecting it to the conceptual structure of prioritarian distributive justice. The in medias res perspective does not arise just anywhere in the middle of the chain of events associated with an outbreak of disease but is rather the point at which all distributively salient differences between persons have resolved themselves and the only differences that remain are unconnected to any of the intuitive concerns of distributive justice. I have proposed that this happens after initial exposure to a disease but before persons finally become infected. But for some diseases it may happen earlier. Nothing rules out that a disease's patterns of exposure may disrespect all intuitively salient distributive categories and so appear as a matter of irreducible luck (and SARS may present patterns of exposure that approximate this case, although it is far from clear that the Western response to SARS was free from nativist anti-Asian sentiment). For such diseases, distributive assessments of individual burdens may perhaps appropriately be made from a point of view before any outbreak has occurred and in a way that spreads risks of exposure evenly across all persons (in which case the in medias res point of view, identified by the structural test set out here, coincides with the ex ante point of view). And such diseases may perhaps fairly be combated using quarantines.

58. Gambles, incidentally, also present everyday cases of Acts of God, or irreducible luck. The players at a roulette table, for example, will in the end enjoy distinct outcomes depending upon the spin of the wheel and the path of the ball. But these distinct outcomes are completely unrelated to any intuitively compelling difference between the persons who bear them indeed, this is precisely roulette's charm for the player. And this is another reason for which a prioritarian might take an ex ante view of games of chance.

59. Indeed, such redistribution renders gambling impossible - a gamble depends, as a conceptual matter, on leaving luck within the gamble to lie where it falls. Any effort to redistribute luck within a gamble drafts some gamblers into the service of others and therefore undermines the choices of all gamblers.

60 . The defense against a risk may invoke concrete methods (including the many ways of taking care) that actually prevent the risk's bad outcome from occurring or instead invoke more abstract methods (most notably contracts, including familiar forms of insurance) that provide compensation in case the bad outcome does occur. A similar discussion of converting ordinary risks into gambles (which emphasizes the special case of insurance) appears in R. Dworkin "What is Equality? Part 2: Equality of Resources," Philosophy $ซ$ Public Affairs 10 (1981): 283-345, at 297.

61. This approach, it is worth noting in the margin, is consistent with Perry's observation, reported earlier, that a risk of loss is not itself a harm but only a reflection of epistemic limitations concerning knowledge of certain harms. See note 47 , supra. The distributive burden of an unresolved risk arises not out of the risk itself - which might after all never eventuate - but rather out of the interplay between the risk and the risk-bearer's epistemic limitations. The risk makes these limitations immediately more costly to persons who come to face it: the risk places an unchosen charge on the epistemic limitations of persons who fall subject to it; and this charge applies even to the unresolved risk, and whether or not it eventuates.

62. It is important to emphasize that these considerations do not apply when no alternatives to quarantines are available, so that a society simply cannot control the spread of a disease among those who have been exposed to it. In such cases - one thinks of Plague in early modern Europe, which spread inexorably by vectors that were then unknown and irresistible - unresolved risks of infection cannot be protected against, so that the distributive burden of these risks cannot be liquidated, by any means, and contracting the disease becomes purely a matter of chance and is never the result of a deliberate gamble. In these cases, exposure to the disease may indeed be merely a way-station, from a distributive point of view, so that unresolved risks of infection may not be distributively salient, and quarantines might be distributively justified on the ground that they subject a smaller rather a larger number of persons to individually equivalent burdens.

Even in these circumstances, however, the distributive case for quarantines will be weakened to the extent that the underlying risks of being exposed to an outbreak of disease, and hence subjected to a quarantine, are unequally distributed in ways that trigger distributive concern, for example so that they fall disproportionately on the poor. When this happens, the two arguments concerning the appropriate attitude to unresolved risks will recommend opposed approaches: the first argument, which distinguishes distributively compelling distinctions among persons from irreducible luck, will recommend treating the different 
risks of exposure as distributively salient and condemn quarantines as unfair; the second argument, which distinguishes ordinary luck from deliberate gambles, will recommend looking through unavoidable risks to outcomes and say that quarantines are fair. Both approaches have some intuitive appeal. While it is true, to stick with the example, that quarantines in such a case disproportionately benefit the rich and burden the poor, it is also true that individual rich and poor persons who become infected are just as burdened by their fates as individual poor persons and no more responsible for them.

63. If foregoing vaccinations involves forbidding individual persons from getting vaccinated, then the failure to be vaccinated less obviously resembles a deliberate gamble, at least on the part of persons who would have sought out vaccinations but for the prohibition. At the very least, the resemblance depends upon a supplemental argument, for example about democratic authority, establishing individual responsibility for collective decisions. But there is little justification for prohibiting vaccinations in the kinds of cases at issue (where vaccinations surely fall within the range of the medically reasonable), and this complication may therefore be set aside. The live question is whether to make vaccinations voluntary or mandatory. One argument in favor of making vaccinations mandatory is that persons internalize all of the costs but not all of the benefits of getting vaccinated, so that the rate of voluntary vaccination among persons who rationally pursue their self-interests will fall below the optimal level. See, e.g., C. Bauch, A. Galvani and D. Earn, "Group Interest versus Self-Interest in Smallpox Vaccination Policy," Proceedings of the National Academy of Sciences 100 (2003): 10564.

64 . Notice that this argument retains its force even when vaccinations are less efficient than doing nothing to combat disease. For example, imagine (perfectly plausibly) that the costs of vaccination are higher than I have supposed, and in particular are 1/10 the burden of infection. In this case, the aggregate burden of the vaccination scheme grows to the equivalent of one million infections, which exceeds the aggregate expected burden of doing nothing. It is certainly plausible that a society facing these facts might choose not to vaccinate against the disease. But having so chosen, the society cannot fairly turn instead to a quarantine to control the disease. The option to vaccinate continues to render the risk of infection associated with doing nothing distributively salient (and continues to liquidate this risk, now at $1 / 10$ the burden of infection). Any infections that occur after vaccinations have been foregone therefore remain the result of the choice - the deliberate gamble - not to vaccinate and are once again incapable of underwriting distributive claims.

The argument loses its force only when vaccinations become so much less efficient than quarantines that they no longer present a reasonable alternative means of disease control, so that foregoing them no longer resembles a deliberate gamble. It is a difficult question when this point is reached. One possible view - which maximally imports prioritarian principles into the account of gambles - is that vaccinations cease to present a reasonable alternative to quarantines only when their individual costs come to exceed the individual costs of quarantines. I am sceptical of this view, which seems to me overly rigorous, but I shall not take up the question here.

65. This explains, incidentally, why quarantines cannot be rehabilitated by building a quarantine policy into the decision not to employ vaccinations, so that the prospect of quarantines becomes a part of the gamble involved in foregoing vaccinations. Because quarantines concentrate the burdens of infectious disease among the first to become exposed and risks of exposure are uneven in distributively salient ways (for example, fall more heavily on the poor than on the rich), building the prospect of quarantines into the decision not to vaccinate entrenches the unfairness of the gamble itself. Distributive justice cannot condone this practice, through which the gamble involved in foregoing vaccinations becomes a device for exacerbating an already unfair division of risk among the gamblers.

In presenting this argument, I have made the simplifying assumption that quarantines confine all persons whose initial risks of exposure were high and protect all persons whose initial risks of exposure were low. Real quarantines, of course, will not typically be so neat but will instead confine some members of each group and protect others (although in concentrations that reflect underlying differences in risks of exposure). This opens up the possibility that quarantines might split the group that faces the greatest risk rather than uniting that population and segregating it from low risk group. And accordingly, the greatest beneficiaries of a quarantine that concentrates the burdens of infectious disease upon some members of the group that faced the greatest initial risk of exposure may be other members of this same group (for example, a quarantine that principally confines the urban poor may most benefit the as yet unexposed urban poor, whose chances of exposure are particularly high, and may benefit the suburban rich, whose chances of exposure are lower in any case, much less). This possibility raises difficult questions, which I shall not take up here, about how distributive justice should balance the claims of the worst-off against those of the next-worst-off.

66. Note finally that some of these arguments may also be applied within quarantines, to yield a distributive ethics of quarantine administration. For example, certain forms of intensive quarantine management (including, most extremely, solitary confinement within quarantines) can reduce within-quarantine rates of infection, although only at the heavy cost of subjecting those confined to quarantines to such intrusive and burdensome regimes. One might ask, therefore, whether these regimes are justified, that is, whether they are efficient and whether they are fair.

The second question - about fairness - turns on the individual burdens associated with the various forms of quarantine management. These burdens depend upon whether withinquarantine risks of infection should be assessed $e x$ ante or $e x$ post. And this question turns on whether the availability of within-quarantine methods of reducing new infections converts the decision not to employ these methods (perhaps because they are inefficient) into a deliberate gamble and therefore liquidates the distributive burdens of within-quarantine risks of infection at the individual costs of adopting these methods.

67. This thought may be brought within the orbit of distributive justice by proposing that the worse-off should not be given lexicographic priority (so that arbitrarily large gains to efficiency must be sacrificed to secure arbitrarily small benefits for the worseoff) but instead only some more moderate preference (so that sufficiently great gains to efficiency can justify sufficiently small additional burdens for the worse-off). This suggestion does not fit comfortably within prioritarian theory, however, because it is difficult to see how something less than lexicographic priority for the worse-off may be justified without making reference some idea of aggregates of benefit and burden of the sort that the prioritarian view is inclined to declare irrelevant to moral evaluation. It remains intuitively appealing nevertheless.

68. Compensation remains attractive in this connection, although as I remarked earlier, see note 24, supra, many of the harms that quarantines impose are not compensable. 


\title{
Off with theiro Heads: The Need to Criminalize some forms of Scientific Misconduct
}

\author{
Barbara K. Redman and Arthur L. Caplan
}

\section{A Long History of Disturbing Scandals}

A $\mathrm{n}$ increasingly long line of high-profile scientific misconduct cases raises the question of whether regulatory policy ought to incorporate more rigorous sanctions for investigators and their institutions. Broad and Wade ${ }^{1}$ graphically describe these cases through the early 1980s. They continue to recent times with the cases of Evan Dreyer, ${ }^{2}$ Kimon Angelides and Robert Liburdy, ${ }^{3}$ Justin Radolf, ${ }^{4}$ and others. In addition, recent Congressional investigation into conflict of interest concerns surrounding consulting by National Institutes of Health scientists ${ }^{5}$ has raised further questions about ethical standards. The record of continuing scandal suggests that current policy may not be optimal for controlling scientific misconduct. Would an alternative policy better minimize its incidence and associated costs?

\section{What Should Be the Goals of Public Policy Regarding Misconduct?}

What should we expect of public policy governing misconduct by American scientists? Surely the public has a right to presume that its tax money is being spent wisely and that any economic rewards from taxpayer funded research are used prudently and in the public interest. The public should also assume that the laws and regulations governing misconduct will protect research subjects from harm. Public policy should also insure the integrity of science so that false, inaccurate or fraudulent findings do not become integrated into the body of scientific knowledge. Codes of ethics for a number of scientific societies support these goals. ${ }^{6}$ And the public should expect that treatment for gross misconduct on the part of scientists and biomedical researchers will be equivalent to that in other sectors of American life.

\section{Current Policy}

Recent policy governing scientific misconduct dates from the Health Research Extension Act of 1985, which requires institutions receiving federal funding to establish procedures for addressing scientific misconduct, and to report annually to the federal government about their activities. ${ }^{7}$ Administrative structures to regulate misconduct in research funded by the Public Health Service (PHS) were established in 1989 and have evolved through several iterations of name, functions and organizational placement to the current Office of Research Integrity (ORI).

Investigative processes have developed from informal ones traditional to the scientific community to those which incorporate safeguards to insure due process at the ORI level (although not required at the institutional level). ${ }^{8}$ ORI's role has evolved from direct intervention in the investigation and judgment

Barbara K. Redman, Ph.D., currently serves as Dean and Professor of the Wayne State University, College of Nursing and Visiting Scholar, University of Pennsylvania Center for Bioethics. Prior to joining Wayne State, Dean Redman earned her Bachelor of Science degree in Nursing from South Dakota State University; Master of Education in Nursing Education from University of Minnesota; Doctor of Philosophy from the University of Minnesota; and a Master of Bioethics from the Unizersity of Pennsylzania. Arthur L. Caplan, Ph.D., currently serves as the Emmanuel and Robert Hart Professor of Bioethics, Chair of the Department of Medical Ethics and the Director of the Center for Bioethics at the University of Pennsylvania in Philadelphia. Born in Boston, Caplan did his undergraduate work at Brandeis University, and did his graduate work at Columbia University where he received a Ph.D in the history and philosophy of science in 1979. 